\title{
Flexural buckling of elliptical hollow section columns
}

\author{
T. M. Chan ${ }^{1}$ and L. Gardner ${ }^{2}$
}

\begin{abstract}
${ }^{1}$ Assistant Professor in Structural Engineering, School of Engineering, the University of Warwick, Coventry, CV4 7AL, United Kingdom. Email: t.m.chan@warwick.ac.uk

${ }^{2}$ Senior Lecturer, Department of Civil and Environmental Engineering, South Kensington Campus, Imperial College London, SW7 2AZ, United Kingdom. Email: leroy.gardner@imperial.ac.uk
\end{abstract}

\begin{abstract}
Complementary to recent studies on the cross-section behavior of elliptical hollow sections, investigations into the member response have also been performed and described in this paper. The first stage of these investigations involved a series of precise column buckling tests on hot-finished steel elliptical hollow sections. In total, 24 flexural buckling tests about the minor and major axes were carried out. Specimen sizes and lengths were carefully chosen in order to cover a wide range of both cross-section and member slendernesses. The non-dimensional column slenderness of the test specimens varied between 0.19 and 1.58. Measurements were taken of specimen geometry, global initial geometric imperfections and tensile material properties. Key results from the tests including the full load-deformation histories have been presented and discussed. The test results have also been supplemented by 158 numerically generated results, allowing a wider range of geometries to be investigated. Design rules for the member buckling resistance of elliptical hollow section columns have been proposed and verified by means of reliability analysis. The presented results are the first member buckling tests on elliptical hollow sections, and represent part of the development of comprehensive structural design rules for these sections.
\end{abstract}


CE Database subject headings: Buckling; Columns; Compression; Design; Hollow sections; Laboratory tests; Numerical analysis; Slenderness ratio; Steel structures.

\section{Introduction}

Tubular members are widely used for exposed structural elements owing to their efficiency and aesthetic appearance. The familiar range of tubular members currently comprises square, rectangular and circular hollow sections. However, elliptical hollow sections have been recently introduced to the construction market, and structural columns are becoming a popular application. Elliptical hollow sections can offer greater efficiency than circular hollow sections, particularly when subjected to eccentric loading (generating a bending moment about the stronger axis) or when differing end restraints or bracings exist about the two principal axes (altering the effective column buckling lengths). Recent examples of the use of elliptical hollow sections as columns may be found at the airports at Heathrow in London, UK (Corus 2006a) and Barajas in Madrid, Spain (Viñuela-Rueda and Martinez-Salcedo 2006). Previous studies of elliptical hollow sections conducted by the authors include design proposals for cross-section classification (Gardner and Chan 2007), cross-section design strength in compression (Chan and Gardner 2008a) and bending about both principal axes (Chan and Gardner 2008b) and combined shear and bending (Gardner et al. 2008). Recent studies on the elastic buckling of elliptical hollow sections (Zhu and Wilkinson 2006; Ruiz-Teran and Gardner 2008), the response of filled elliptical tubes (Roufegarinejad and Bradford 2007; Zhao et al. 2007; Yang et al. 2008) and the behaviour of connections to EHS (Bortolotti et al. 2003; Choo et al. 2003; Pietrapertosa and Jaspart 2003; Willibald et al. 2006) have also been performed. This paper describes an investigation of the buckling strength of elliptical hollow section columns. Detailed experimental and numerical studies are described and structural design rules are proposed. 


\section{Experimental studies}

A comprehensive full-scale laboratory testing programme on EHS (grade S355), manufactured by Corus Tubes (Corus 2006b), has been conducted at Imperial College London. To date, material tensile coupon tests and cross-section capacity tests in compression (Chan and Gardner 2008a), bending (Chan and Gardner 2008b) and shear (Gardner et al. 2008) have been performed. This paper focuses on the member behavior of pin-ended, elliptical hollow section columns. The tested EHS had an aspect ratio of two, overall cross-section dimensions of $150 \times 75 \mathrm{~mm}$ and thicknesses of $4 \mathrm{~mm}, 5 \mathrm{~mm}$ and $6.3 \mathrm{~mm}$. A total of six material tensile coupon tests and twenty four column buckling tests were carried out.

\section{Tensile coupon tests}

Material tensile coupon tests were performed to determine the basic engineering stress-strain response of the material for each of the tested section sizes. The obtained material data were used to facilitate the analysis of the column test results and were incorporated into the numerical simulations to replicate the response of the tested specimens. Full details of the tensile tests have been reported by the authors (Chan and Gardner 2008a), whilst a summary of the test results is given in Table 1.

\section{Flexural buckling tests}

The primary aim of the column tests was to investigate the flexural buckling response of EHS pinended compression members under axial loading. The pin-ended conditions were provided by hardened steel knife-edges fixed to the ends of the specimens. The specimen lengths were carefully chosen to provide a spectrum of member slendernesses. The nominal pin-ended column lengths were $0.7 \mathrm{~m}, 1.5 \mathrm{~m}, 2.3 \mathrm{~m}$ and $3.1 \mathrm{~m}$ (Fig. 1), with the corresponding $\mathrm{L}_{\mathrm{cr}} / \mathrm{i}$ ranging from 15 to 117 
(and non-dimensional column slenderness ranging from 0.19 to 1.58 ), where $\mathrm{L}_{\mathrm{cr}}$ is the buckling (effective) length in the buckling plane considered and $i$ is the radius of gyration about the relevant buckling axis (determined using the properties of the gross cross-section). The general testing configuration is depicted in Fig. 2. For column specimens where the measured global imperfection was less than L/1000, an eccentricity of loading was applied such that the combined imperfection plus eccentricity was equal to L/1000. For three of the columns $-150 \times 75 \times 6.3-\mathrm{C} 1,150 \times 75 \times 5-\mathrm{C} 3$ and $150 \times 75 \times 5-C 5$ - the measured initial imperfections were greater than L/1000; for these specimens, the load was applied concentrically. The loading was recorded by a $1000 \mathrm{kN}$ load cell located at the top end of the columns. Vertical displacement was measured at the loaded end of the columns by two LVDTs, whilst two additional LVDTs were positioned at each end of the columns to measure end rotation. Two LVDTs were also located at the mid-height of the columns to measure the lateral deflection in the major and minor axes directions. Four linear electrical resistance strain gauges were affixed to the extreme fibers of the section at a distance of $20 \mathrm{~mm}$ from the mid-height to avoid contact with the LVDTs. Load, strain, displacement and input voltage were all recorded using the data acquisition equipment DATASCAN and logged using the DSLOG computer package.

The geometry of an elliptical hollow section is depicted in Fig. 3 and the mean measured dimensions and maximum global geometric imperfections $\omega_{\mathrm{g}}$ (determined by employing feeler gauges to measure the clearance between the columns and a flat datum) of the test specimens (based on specimen lengths ignoring the knife edges) are summarized in Table 2. Local geometric imperfections were not measured in this study since the proportions of the cross-sections examined were relatively stocky and insensitive to local buckling. For thin-walled hollow sections, such measurements would typically be performed (Young and Chen 2008). Geometric properties for the EHS specimens are defined using the exact formulae adopted by the authors in previous studies 
(Chan and Gardner 2008a, b; Gardner and Chan 2007). The key results from the column tests have been reported in Table 2. Full load-deformation relationships for the column tests are reported in Chan (2007) and typical structural responses are described in the following sections.

\section{Load versus vertical displacement response}

The normalized load-vertical displacement response for the EHS $150 \times 75 \times 6.3$ pin-ended columns of $0.7 \mathrm{~m}$ length are shown in Fig. 4. In the figure, $\mathrm{C} 1$ represents the column buckling response about the $\mathrm{z}-\mathrm{z}$ axis (minor axis) whilst $\mathrm{C} 2$ illustrates the response about the $\mathrm{y}-\mathrm{y}$ axis (major axis). According to the cross-section classification measure defined by Gardner and Chan (2007) and by Ruiz-Teran and Gardner (2008), this cross-section is deemed to be fully effective in pure compression. Both columns have demonstrated a similar peak load because the columns are relatively stocky, though a significant difference in the unloading behavior may be observed. This can be explained by considering the effects of inelastic local buckling and plastic hinge formation at the most heavily loaded cross-section (at the column mid-height). For the column buckling about the $\mathrm{z}-\mathrm{z}$ axis (column $\mathrm{C} 1$ ), the maximum compressive stress coincides with the flattest portion of the cross-section which is most susceptible to local buckling. Local buckling heralds a loss of second moment of area resulting in a marked drop in load. Conversely, for column C2 where buckling is about the y-y axis, the maximum compression coincides with the stiffest region of the cross-section, which is resistant to local buckling, resulting in a more gradual loss of load carrying capacity.

\section{Load versus lateral deflection response}

Figs 5 and 6 show the load versus lateral deflection response of the two $3.1 \mathrm{~m}$ long EHS $150 \times 75 \times 6.3$ pin-ended columns, buckling about the minor and major axes. In the figures, the elastic buckling load $\mathrm{N}_{\mathrm{cr}}$ (given by Eq. (1)) and the plastic yield load $\mathrm{N}_{\mathrm{y}}$ (given by Eq. (2)) have also been plotted. 


$$
\begin{aligned}
& \mathrm{N}_{\mathrm{cr}}=\frac{\pi^{2} \mathrm{EI}}{\mathrm{L}_{\mathrm{cr}}^{2}} \\
& \mathrm{~N}_{\mathrm{y}}=\mathrm{Af}_{\mathrm{y}}
\end{aligned}
$$

where $\mathrm{E}$ is the Young's modulus, I is the second moment of area about the relevant buckling axis, $\mathrm{L}_{\mathrm{cr}}$ is the buckling (effective) length in the buckling plane considered, $\mathrm{A}$ is the gross cross-section area and $f_{y}$ is the material yield stress. Eqs (1) and (2) represent the two theoretical upper bounds to column resistance. For stockier members, the ultimate load is dominated by the plastic yield load whilst for slender members, the ultimate load approaches the Euler buckling load. For the column under consideration, when buckling about the minor axis (Fig. 5), the elastic buckling load $\mathrm{N}_{\mathrm{cr}}$ is below the yield load $\mathrm{N}_{\mathrm{y}}$, whilst when buckling about the major axis (Fig. 6), the elastic buckling load is above the yield load. The relative influence of the two bounds may be seen in Figs 5 and 6 .

In addition to the inclusion of $\mathrm{N}_{\mathrm{cr}}$ and $\mathrm{N}_{\mathrm{y}}$ in Figs 5 and 6 , the results of a second order elastic analysis and a rigid plastic analysis have also been shown. The second order elastic analysis was performed on the assumption that the unloaded column has an initial sinusoidal bow of maximum amplitude $\omega_{\mathrm{i}}$. The maximum additional lateral deflection $\omega$ arising under increased loading $\mathrm{N}$ may be determined from Eq. (3) provided the column remains elastic.

$$
\omega=\frac{\omega_{\mathrm{i}}}{1-\left(\mathrm{N} / \mathrm{N}_{\mathrm{cr}}\right)}-\omega_{\mathrm{i}}
$$

The amplitude of the initial bow was selected to achieve the best representation of the response of the tested columns - for column $150 \times 75 \times 6.3-\mathrm{C} 7$ (Fig. 5), the required initial bow was found to be approximately L/500, whilst for column $150 \times 75 \times 6.3$-C8 (Fig. 6), a value of approximately L/1000 was found to be suitable. In the latter case, the required initial bow was similar to the total test imperfection (initial bow plus applied load eccentricity), whilst for the $150 \times 75 \times 6.3-\mathrm{C} 7$, a larger 
imperfection than was measured in the test was required - interestingly L/500 was also the imperfection amplitude that resulted in best agreement between the FE model and the test (see Table 3), suggesting that a slightly larger imperfection (geometric or residual stresses) may have actually existed for this test specimen.

For the second order rigid plastic analysis, reference may be made to the concentrically loaded pinended column shown in Fig. 7. By assuming that all deformation is concentrated in a plastic hinge at the mid-height of the column, the axial load $\mathrm{N}$ that can be sustained under increased lateral deflection may be determined by examining the stress distribution of Fig. 8. As illustrated in Fig. 8, the central compressive region (zone 2) is responsible for resisting the axial load N, whilst the two outer regions (zones 1 and 3) form a couple to resists the second order moment $\mathrm{M}_{2}=\mathrm{N \omega}$ arising from the lateral deflection $\omega$ (Allen and Bulson 1980). Based on this stress model, the second order rigid plastic boundary has been derived and plotted in Figs 5 and 6 . The test results demonstrate sound agreement with the theoretical models, with the general response being characterized by the envelope of the two second order boundaries. The initial elastic response concurs with the second order elastic analysis while the unloading behavior merges into the second order rigid plastic line. These test results have been replicated numerically and used for the validation of column buckling curves in the following sections.

\section{Numerical simulations}

A numerical modeling investigation, utilizing the finite element (FE) package ABAQUS (2006), was implemented alongside the experimental programme. The objectives of the investigation were to (1) replicate the experimental results, (2) validate the numerical models and (3) perform parametric studies. The elements chosen for the FE models were 4-noded, reduced integration shell 
elements with six degrees of freedom per node, designated as S4R in the ABAQUS (2006) element library, and suitable for thin or thick shell applications. A uniform mesh density was carefully chosen by carrying out a mesh convergence study based on elastic eigenvalue predictions with the aim of achieving accurate results whilst minimizing computational effort. A suitable mesh size was found to be $2 \mathrm{a} / 10(\mathrm{a} / \mathrm{b}) \times 2 \mathrm{a} / 10(\mathrm{a} / \mathrm{b}) \mathrm{mm}$, where $\mathrm{a}$ and $\mathrm{b}$ are defined in Fig. 3 . In total, 158 numerical simulations were carried out, including validation studies, sensitivity studies and parametric studies.

The column tests were modeled using the measured dimensions of the test specimens and measured material stress-strain data. Initial global geometric imperfections were incorporated in the numerical model by means of a global half-sine wave given by $\omega_{\mathrm{g}} \sin (\pi \mathrm{x} / \mathrm{L})$, where $\mathrm{x}$ is the distance along the specimen, $\mathrm{L}$ is the specimen length and $\omega_{\mathrm{g}}$ is the global imperfection amplitude. A range of global imperfection amplitudes $\omega_{\mathrm{g}}$ was studied - in addition to the measured imperfection values (excluding applied load eccentricity), four fixed fractions of the specimen length $\mathrm{L}(\mathrm{L} / 250, \mathrm{~L} / 500$, L/1000 (representing the total test imperfection including applied load eccentricity) and L/2000) were considered. A similar spectrum of global imperfection amplitude was studied by Batterman and Johnston (1967) and Gardner and Nethercot (2004). The amplitudes of L/250 and L/500 reflect the current allowable out-of-straightness tolerance for elliptical hollow section tubes in Europe (EN 10210-2 2006), whilst L/500 is the tolerance limit in Europe (EN 10210-2 2006), North America (ASTM A501 2005) and Australia (AS 1163 1991) for other tubular members.

The presence of longitudinal residual stresses in structural members can have a significant influence on column buckling strengths, by causing premature yielding of the cross-section resulting in a reduction in stiffness and loss of load carrying capacity. Residual stresses are induced primarily during the production process. For cold-formed sections, residual stresses are principally induced 
through plastic deformation, whilst for hot-finished and welded sections, uneven cooling is the main source of residual stresses. The elliptical hollow sections considered in the present study are hotfinished structural sections; the residual stresses are therefore primarily induced through uneven cooling. In tubes, uneven cooling arises as a result of the differing thermal conditions present at the outer and inner surfaces of the sections, with the outer surface cooling more rapidly. This generally leaves the outer surface of the tube in longitudinal and radial compression, with equilibrating tension on the inner surface. In the development of the European column buckling curve for hotfinished tubular sections (Beer and Schulz 1970), a representative residual stress pattern based on measurements from circular tubes was employed. The adopted distribution was symmetrical through the thicknesses with compressive residual stresses on the outer surface and tensile residual stresses on the inner surface, though the experimental findings of Stamenkovic and Gardner (1983) exhibited a contradictory trend. The magnitude of both tensile and compressive residual stresses was in the region of $15 \%$ of the material yield stress. It may be inferred that residual stresses in elliptical tubes would be of similar magnitude and distribution to those in circular tubes, though since no residual stresses measurements were performed in this study, further investigation would be required to verify this. Two observations indicated that the level of residual stresses in the studied hot-finished EHS was low: (1) negligible deformations occurred when the material tensile coupons were machined from the cross-sections and (2) a distinct yield point was seen in both the tensile coupon results and the stub column results (Chan and Gardner 2008a), which high residual stresses would erode. For these reasons, residual stresses were not explicitly incorporated into the numerical models.

The true material stress-strain relationships were generated from the engineering stress-strain curves obtained from the tensile coupon tests. The material non-linearity was incorporated into the numerical models by means of a piecewise linear stress-strain model to replicate, in particular, the strain-hardening region. Boundary conditions were applied to model pin end conditions at the ends 
of the columns. The modified Riks method (ABAQUS 2006) was employed to solve the geometrically and materially non-linear column models, which enabled the post-ultimate behavior to be traced. The numerical failure mode of $150 \times 75 \times 6.3-\mathrm{C} 4$ is shown in Fig. 9 and compared with the corresponding deformed test specimen. Results of the numerical simulations are tabulated in Table 3, in which, the ratios between the ultimate FE and experimental axial loads are shown and compared for different imperfection levels.

Replication of test results was found to be satisfactory with the numerical models able to successfully capture the initial stiffness, ultimate capacity, general load-deformation response and failure patterns observed in the tests. Comparison between test and FE results are shown for columns $150 \times 75 \times 4-\mathrm{C} 5$ (minor axis buckling) and $150 \times 75 \times 6.3-\mathrm{C} 8$ (major axis buckling) in Figs 10 and 11, respectively. The anticipated sensitivity to imperfections has been reflected in the numerical results in particular among the specimens of intermediate slenderness which showed the greatest variation in response. For example, in the case of the $150 \times 75 \times 6.3-\mathrm{C} 8$ models $\left(\mathrm{L}_{\mathrm{cr}} / \mathrm{i}=\right.$ 67), the ultimate load reduces by approximately $30 \%$ with an increase of imperfection amplitude from $\mathrm{L} / 2000$ to $\mathrm{L} / 250$.

Having verified the general ability of the FE models to replicate the column test behavior for EHS with an aspect ratio of two, a series of parametric studies was conducted. The primary aim of the parametric studies was to investigate the influence of cross-section slenderness, aspect ratio and member slenderness on the column load carrying capacity. The obtained results were also used to assess column buckling design curves. A piecewise linear material stress-strain model was developed from the tensile coupon tests conducted on the $150 \times 75 \times 6.3$ sections and adopted throughout the parametric studies (see Fig. 12). Initial geometric imperfections in the non-linear parametric analyses were of the form of a half-sine wave with an amplitude $\omega_{\mathrm{g}}$ of $\mathrm{L} / 1000$, which corresponded to the total test imperfection (geometric bow plus applied load eccentricity) and 
provided the best agreement between FE and test results (Table 3). This magnitude is the same as that employed in the formulation of the European column buckling curves (Beer and Schulz 1970; Galambos 1998) and the Australian column curves (Rotter 1982; Beedle 1991). It is worth noting that the current AISC Standard employed L/1500 (Beedle 1991; Galambos 1998) as the governing out-of-straightness in developing the column design curves. The section sizes considered in the parametric studies were $150 \times 150,150 \times 75$ and $150 \times 50$ with varying thicknesses and a range of column lengths to extend the investigation to higher member slenderness. The results have been utilized for the validation of proposed column buckling curves for elliptical hollow sections, as discussed in the following section.

\section{Buckling resistance of members}

In this section, the results of the EHS column buckling tests are examined and compared with the current column design specifications adopted in Europe, North America and Australia; on the basis of the comparisons, design recommendations are presented.

\section{Member slenderness for flexural buckling}

European Standard (EC 3)

According to EN 1993-1-1 (2005), the non-dimensional member slenderness $\lambda_{\mathrm{EC}}$ is given by

$$
\begin{array}{cl}
\lambda_{\mathrm{EC}}=\sqrt{\frac{\mathrm{Af}_{\mathrm{y}}}{\mathrm{N}_{\mathrm{cr}}}}=\frac{\mathrm{L}_{\mathrm{cr}}}{\mathrm{i} \pi} \sqrt{\frac{\mathrm{f}_{\mathrm{y}}}{\mathrm{E}}} & \text { for Class } 1 \text { to } 3 \text { (fully effective) sections (4) } \\
\lambda_{\mathrm{EC}}=\sqrt{\frac{\mathrm{A}_{\mathrm{eff}} \mathrm{f}_{\mathrm{y}}}{\mathrm{N}_{\mathrm{cr}}}}=\frac{\mathrm{L}_{\mathrm{cr}}}{\mathrm{i} \pi} \sqrt{\frac{\left(\mathrm{A}_{\mathrm{eff}} / \mathrm{A}\right) \mathrm{f}_{\mathrm{y}}}{\mathrm{E}}} & \text { for Class } 4 \text { (slender) sections }
\end{array}
$$

where $\mathrm{L}_{\mathrm{cr}}$ is the buckling (effective) length in the buckling plane considered, $\mathrm{i}$ is the radius of 
gyration about the relevant buckling axis (determined using the properties of the gross cross-section) and $\mathrm{A}_{\mathrm{eff}}$ is the effective cross-sectional area, a proposal for which has been made for EHS by Chan and Gardner (2008a).

North American Standard (AISC 360)

In accordance with AISC 360 (2005) and Tide (1985, 2001), the corresponding non-dimensional member slenderness $\lambda_{\text {AISC }}$ is given by

$$
\begin{array}{cc}
\lambda_{\mathrm{AISC}}=\frac{\mathrm{L}_{\mathrm{cr}}}{\mathrm{i} \pi} \sqrt{\frac{\mathrm{f}_{\mathrm{y}}}{\mathrm{E}}} & \text { for fully effective sections } \\
\lambda_{\mathrm{AISC}}=\frac{\mathrm{L}_{\mathrm{cr}}}{\mathrm{i} \pi} \sqrt{\frac{\mathrm{Qf}_{\mathrm{y}}}{\mathrm{E}}} & \text { for slender sections }
\end{array}
$$

where $\mathrm{Q}$ is the slenderness reduction factor which defines the ratio of the stress at local buckling to the yield stress (AISC 360 2005).

\section{Australian Standard (AS 4100)}

According to AS 4100 (1998), the equivalent non-dimensional member slenderness $\lambda_{\mathrm{AS}}$ is given by

$$
\begin{array}{ll}
\lambda_{\mathrm{AS}}=\frac{\mathrm{L}_{\mathrm{cr}}}{\mathrm{i}} \sqrt{\frac{\mathrm{f}_{\mathrm{y}}}{250}}=\frac{\mathrm{L}_{\mathrm{cr}}}{\mathrm{i} \pi} \sqrt{\frac{\mathrm{f}_{\mathrm{y}}}{\mathrm{E}}}\left(\pi \sqrt{\frac{\mathrm{E}}{250}}\right) & \text { for fully effective sections } \\
\lambda_{\mathrm{AS}}=\frac{\mathrm{L}_{\mathrm{cr}}}{\mathrm{i}} \sqrt{\frac{\mathrm{k}_{\mathrm{f}} \mathrm{f}_{\mathrm{y}}}{250}}=\frac{\mathrm{L}_{\mathrm{cr}}}{\mathrm{i} \pi} \sqrt{\frac{\mathrm{k}_{\mathrm{f}} \mathrm{f}_{\mathrm{y}}}{\mathrm{E}}}\left(\pi \sqrt{\frac{\mathrm{E}}{250}}\right) & \text { for slender sections }
\end{array}
$$

where $\mathrm{k}_{\mathrm{f}}$ is defined as the ratio of the effective area to the gross area of the cross-section.

Table 4 summarizes the key results of the column tests where the ultimate load $N_{u}$ has been normalized by the yield load $\mathrm{N}_{\mathrm{y}}\left(=\mathrm{Af} \mathrm{f}_{\mathrm{y}}\right)$ or the effective yield load $\mathrm{A}_{\text {eff }} \mathrm{f}_{\mathrm{y}}$. According to the slenderness parameters and limits proposed by Gardner and Chan (2007) and by Ruiz-Teran and 
Gardner (2008), the tested EHS with wall thicknesses of $4 \mathrm{~mm}$ are Class 4 (slender), and the ultimate loads have therefore been normalized by $\mathrm{A}_{\text {eff }} f_{\mathrm{y}}$. The $5 \mathrm{~mm}$ and $6.3 \mathrm{~mm}$ thick sections are classified as Class 1-3 (fully effective) and thus, the ultimate loads have been normalized by $\mathrm{Af}_{\mathrm{y}}$. The normalized test results have also been plotted in Figs 13 and 14. For comparison, existing column test data for circular hollow sections (CHS) have also been added to Figs 13 and 14 (Janns et al. 1989). From these figures, it may be seen that the test results for buckling about the minor (z$\mathrm{z})$ and major (y-y) axes follow a similar trend alongside their circular counterparts.

\section{Column buckling curves}

European Standard (EC 3)

The concept of multiple column curves adopted in Europe (Beer and Schultz 1970; Jacquet 1970; Sfintesco 1970) forms the basis of the column design criteria in Eurocode 3 (EN 1993-1-1 2005). A set of five buckling curves described by the Ayrton-Perry (Ayrton and Perry 1886; Robertson 1925; Maquoi and Rondal 1978) formula is adopted in this European standard. For hollow sections, the choice of buckling curve depends on the forming route (hot-finished or cold-formed) and the material yield strength. For hot-finished hollow sections of grade S355, buckling curve ' $a$ ' is recommended. In Eurocode 3, buckling curves are presented in the form given by Eq. (10). The resulting buckling reduction factor $\chi=$ buckling resistance/cross-section resistance $\left(\mathrm{N}_{\mathrm{b}} / \mathrm{N}_{\mathrm{c}}\right)$ has been plotted in Fig. 13.

$$
\chi=\frac{\mathrm{N}_{\mathrm{b}}}{\mathrm{N}_{\mathrm{c}}}=\frac{1}{\Phi+\sqrt{\Phi^{2}-\lambda_{\mathrm{EC}}^{2}}} \quad \text { but } \chi=\mathrm{N}_{\mathrm{b}} / \mathrm{N}_{\mathrm{c}} \leq 1
$$

where $\Phi=0.5\left[1+\alpha\left(\lambda_{\mathrm{EC}}-0.2\right)+\lambda_{\mathrm{EC}}^{2}\right]$ and $\alpha$ is an imperfection factor (equal to 0.21 for buckling curve 'a'). 
A single column curve is currently adopted in North America (AISC 360 2005). This column curve is derived from the three column curves proposed by the Structural Stability Research Council (Bjorhovde and Tall 1971; Bjorhovde 1972, 1978; Galambos 1998) and can be described by basic column equations which have been derived empirically based on test data (Tide 1985, 2001; Beedle 1991). The AISC column curve is defined by Eqs (11) and (12) and has been plotted in Fig. 13.

$$
\begin{array}{ll}
\frac{\mathrm{N}_{\mathrm{b}}}{\mathrm{N}_{\mathrm{c}}}=0.658^{\lambda_{\text {AISC }}^{2}} & \text { for } \lambda_{\mathrm{AISC}} \leq 1.5 \\
\frac{\mathrm{N}_{\mathrm{b}}}{\mathrm{N}_{\mathrm{c}}}=\frac{0.877}{\lambda_{\text {AISC }}^{2}} & \text { for } \lambda_{\mathrm{AISC}}>1.5
\end{array}
$$

\section{Australian Standard (AS 4100)}

Column design curves, based on the multiple column curve concept are also adopted in the Australian Standard (Rotter 1982; Trahair and Bradford 1998; AS 4100 1998). For hollow sections, the choice of buckling curve depends on the forming route (hot-formed, cold-formed (stress relieved) or cold-formed (not stress relieved)) and the cross-section slenderness. For hot-finished hollow sections of Class 1-3 (fully effective), the reduction factor $\alpha_{c}=\mathrm{N}_{\mathrm{b}} / \mathrm{N}_{\mathrm{c}}$ can be described by Eq. (13) which has been plotted in Fig. 13. The slenderness $\lambda_{\mathrm{AS}}$ has been divided by $\pi \sqrt{\mathrm{E} / 250}$ for consistency and direct comparison with the other Standards considered.

$$
\alpha_{c}=\frac{N_{b}}{N_{c}}=\xi\left\{1-\sqrt{\left[1-\left(\frac{90}{\xi\left(\lambda_{\mathrm{AS}}+\alpha_{\mathrm{a}} \alpha_{\mathrm{b}}\right)}\right)^{2}\right]}\right\}
$$

where $\alpha_{b}$ is equal to -1.0 for Class 1-3 (fully effective) sections and $\xi$ and $\alpha_{a}$ are defined in AS 4100 (1998).

\section{Proposals, reliability analyses and discussion}


As shown in Fig. 13, the buckling curves for hot-finished hollow sections from the three Standards considered generally follow each other closely, with the AS 4100 curve being slightly higher over the full range of member slenderness. The AISC curve is marginally lower than the EC 3 curve at low and intermediate slenderness. At higher slenderness, all curves converge towards the Euler elastic buckling curve.

Partial (resistance) factors are applied to the nominal column equations given by Eqs (10) to (13) to ensure that the required level of reliability is achieved. In EC 3, this partial factor $\gamma_{\mathrm{M} 1}$ appears in the denominator and is set equal to unity, whereas in AISC 360 and AS 4100, the resistance factors (denoted $\phi_{c}$ and $\phi$, respectively) appear in the numerator and have a value of 0.9 . The 'design' column curves are plotted in Fig. 14. The buckling curves recommended for hot-finished hollow sections in the three Standards considered generally provide a lower bound to the EHS test data and to the numerical results from the described parametric studies on elliptical hollow sections with aspect ratios a/b of 1.0 (CHS), 2.0 and 3.0 (shown by lines in Fig. 14). It is therefore proposed that these buckling curves may also be applied to elliptical hollow sections.

In order to verify the reliability of the buckling resistance functions, standard statistical analyses in accordance with EN 1990 (2002) and AISC 360 (2005) were performed. In the Eurocode analysis, the ratio of mean to nominal yield strengths (i.e. the material over-strength) was taken as 1.16 and the coefficients of variation of yield strength and geometric properties were taken as 0.05 and 0.02 , respectively (Byfield and Nethercot 1997). These values originate from industrial data obtained from European steel producers. For the AISC analysis, the ratio of mean to nominal yield strengths was taken as 1.028 and the coefficients of variation of yield strength and geometric properties were taken as 0.058 and 0.05 , respectively (Bartlette et al. 2003). 
The results of the analyses and a summary of the key statistical parameters are presented in Tables 5 (European analysis) and 6 (AISC analysis). The following symbols are used in the Eurocode analysis: $\mathrm{k}_{\mathrm{d}, \mathrm{n}}$ is the design (ultimate limit states) fractile factor for $\mathrm{n}$ tests, where $\mathrm{n}$ is the population of test data under consideration; $b$ is the average ratio of experimental to model resistance based on a least squares fit to the test data; $V_{\delta}$ is the coefficient of variation of the tests relative to the resistance model; $\mathrm{V}_{\mathrm{r}}$ is the combined coefficient of variation incorporating both model and basic variable uncertainties. The following symbols are used in the AISC analysis: $\mathrm{V}_{\mathrm{Q}}$ is the coefficient of variation of load effects; $V_{R}$ is the combined coefficient of variation incorporating both model and basic variable uncertainties (equivalent to $\mathrm{V}_{\mathrm{r}}$ in Eurocode terminology); $\beta$ is the reliability index. For an acceptable level of reliability, a value of $\gamma_{\mathrm{M} 1}$ less than unity (unity being the adopted partial factor for member in EN 1993-1-1 (2005)) and a value of $\beta$ greater than 2.6 is sought. The results (Tables 5 and 6) indicate that when the 24 tests are considered alone, whilst the AISC requirements are satisfied, the Eurocode outcome is marginal. However, the required level of reliability is achieved for both codes when the test and parametric FE results are considered together. The AS 4100 (1998) buckling curve lies below the Eurocode curve and it may be assumed that this also yield acceptable reliability. Overall, it is recommended that the buckling curves from EN 1993-1-1 (2005), AISC 360 (2005) and AS 4100 (1998) that are currently applied to SHS, RHS and CHS columns can also be adopted for hot-finished EHS columns, buckling about either the major or minor axis.

It is worth noting that the initial out-of-straightness implied by modern column curves is generally less than the corresponding specified maximum fabrication tolerances (Beedle 1991; Galambos 1998). This disparity raises concern over the structural adequacy of real columns in relation to the design strengths provided by the Standards (Bild and Trahair 1989). However, in essence, the formulation of modern column curves is based on fitting a design model to available laboratory test 
results for real columns, and performing statistical analyses to determine suitable resistance factors to achieve lower bound predictions or the required level of reliability. A similar process is also undertaken in the development of other structural design rules. Inherently embedded within the test results are a range of geometric imperfections, residual stresses, load eccentricities and material characteristics.

The fabrication limit on out-of-straightness for circular hollow sections is L/500, where L is the length of the member (EN 10210-2 2006; ASTM A501 2005; AS 1163 1991). However, the basic initial out-of-straightness implied in the development of the current American column curve is L/1500 (Beedle 1991; Galambos 1998), and in the derivation of the current European curve for tubular sections is L/1000 (Beer and Schultz 1970). Clearly, the initial geometric imperfections assumed in the development of both design codes is smaller than the fabrication tolerance, but still significantly greater than the mean value of out-of-straightness observed in tubular columns of approximately L/6300, as reported by Bjorhovde (1977). In the current study, the mean measured initial out-of-straightness for the tested elliptical tubes was approximately L/2000, whilst the fabrication tolerance is L/250 for EHS with major outer diameter (2a) less than $250 \mathrm{~mm}$ and L/500 for larger sections (EN 10210-2 2006). Since it is proposed to adopt the current CHS buckling curves for EHS, the implied initial imperfections in the buckling curves are again lower than the fabrication tolerances. The results obtained herein therefore support the wider research findings that fabrication tolerances may be unduly lax as evidenced by both the observed structural performance and measured imperfections of real columns. Thus, it is recommended that fabrication tolerances for structural steelwork be re-assessed in preference to adjusting buckling curves to accord with current tolerances. It should also be added that fabrication tolerances are based on mill products of substantial length, and may not reflect the initial out-of-straightness of columns of typical structural slenderness (Davison and Birkemoe 1982), and furthermore, for columns in real structures, the presence of end restraint and end moments may significantly reduce the influence of the out-of- 
straightness. In the context of this research, the tested elliptical hollow sections, buckling about either the major or minor axis, have demonstrated similar structural behavior to their circular counterparts, and it is therefore deemed appropriate to adopt the same column curves.

\section{Conclusions}

The compressive response of hot-finished elliptical hollow section (EHS) columns has been examined in this study. A total of twenty four flexural buckling experiments was performed twelve about the minor axis and twelve about the major axis. All tested specimens had a crosssectional aspect ratio of two. Various column lengths were considered to give a range of nondimensional member slenderness from 0.19 to 1.58 . Measurements of initial global geometric imperfections in the EHS columns revealed average values of out-of-straightness of approximately L/2000, and all were within specified tolerances. Residual stresses were not explicitly measured, but minimal deformation of coupons upon machining from the complete sections and a sharply defined yield point observed in stub column tests are both indicative of low residual stress magnitudes in EHS, as is generally the case for other hot-finished tubular sections. The key material properties, geometric measurements and test results from the column buckling tests have been reported. Comparisons of sample load-deflection histories have been made against second order elastic and rigid plastic analytical approaches, revealing good agreement between experimental results and theoretical models.

To extend the pool of structural performance data on EHS columns, a detailed numerical modelling programme was conducted. Verification of the models was carefully performed against all test results using measured material properties and geometries - satisfactory replication of the full loaddeflection histories and failure modes was achieved. Parametric studies were subsequently 
performed to assess the structural response of EHS over a wider range of aspect ratios (from 1.0 to 3.0) and member slendernesses. A total of 158 results were generated numerically.

With the aid of both the experimentally and numerically derived results, the column buckling curves utilized in Europe, North America and Australia were examined. The elliptical hollow section columns were found to exhibit similar structural performance to their circular counterparts and it is therefore proposed that the buckling curves from EN 1993-1-1 (2005), AISC 360 (2005) and AS 4100 (1998) that are currently applied to SHS, RHS and CHS columns can also be adopted for hot-finished EHS columns, buckling about either the major or minor axis. The suitability of these design proposals was verified by means of reliability analyses in accordance with the European and AISC requirements.

\section{Acknowledgements}

The authors are grateful to the Dorothy Hodgkin Postgraduate Award Scheme for the project funding, and would like to thank Corus Tubes for the supply of test specimens and funding contributions, Andrew Orton (Corus Tubes) and Ada Law (Imperial College London) for their technical input and Ron Millward (Imperial College London) for his assistance in the laboratory works. 


\section{Notation}

The following symbols are used in this paper:

\begin{tabular}{|c|c|c|}
\hline A & $=$ & gross cross-sectional area; \\
\hline$A_{\text {eff }}$ & $=$ & effective cross-sectional area; \\
\hline $\mathrm{E}$ & $=$ & Young's modulus; \\
\hline I & $=$ & second moment of area; \\
\hline $\mathrm{L}$ & $=$ & specimen length; \\
\hline $\mathrm{L}_{\mathrm{cr}}$ & $=$ & buckling (effective) length; \\
\hline $\mathrm{M}_{2}$ & $=$ & second order moment $(\mathrm{N} \omega)$; \\
\hline $\mathrm{N}$ & $=$ & applied axial load; \\
\hline $\mathrm{N}_{\mathrm{b}}$ & $=$ & buckling resistance; \\
\hline $\mathrm{N}_{\mathrm{c}}$ & $=$ & cross-section resistance; \\
\hline $\mathrm{N}_{\mathrm{cr}}$ & $=$ & elastic buckling load; \\
\hline $\mathrm{N}_{\mathrm{u}}$ & $=$ & ultimate axial load; \\
\hline $\mathrm{N}_{\mathrm{y}}$ & $=$ & plastic yield load; \\
\hline Q & $=$ & $\begin{array}{l}\text { slenderness reduction factor which defines the ratio of the stress at } \\
\text { local buckling to the yield stress (AISC } 360 \text { 2005); }\end{array}$ \\
\hline $\mathrm{V}_{\delta}$ & $=$ & coefficient of variation of tests relative to resistance model (EN 1990 2002); \\
\hline $\mathrm{V}_{\mathrm{Q}}$ & $=$ & coefficient of variation of load effects (AISC 360 2005); \\
\hline $\mathrm{V}_{\mathrm{r}}$ & $=$ & $\begin{array}{l}\text { combined coefficient of variation incorporating both model and basic variable } \\
\text { uncertainties (EN 1993-1-1 2005); }\end{array}$ \\
\hline $\mathrm{V}_{\mathrm{R}}$ & $=$ & $\begin{array}{l}\text { combined coefficient of variation incorporating both model and basic variable } \\
\text { uncertainties (AISC } 360 \text { 2005); }\end{array}$ \\
\hline 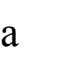 & $=$ & half of the larger outer diameter; \\
\hline
\end{tabular}




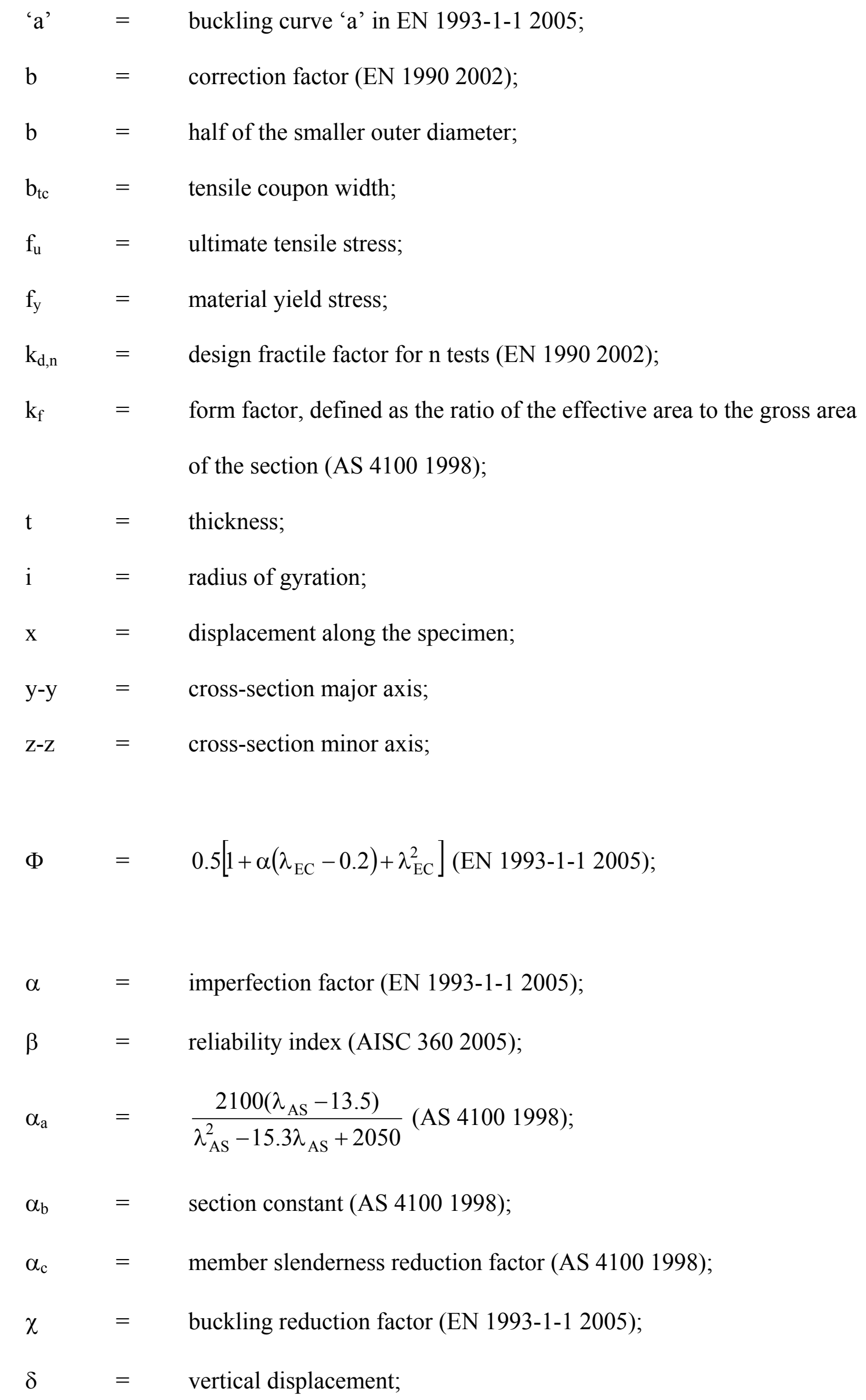




\begin{tabular}{|c|c|c|}
\hline$\phi$ & $=$ & capacity factor (AS 4100 1998); \\
\hline$\phi_{\mathrm{c}}$ & $=$ & resistance factor (AISC 360 2005); \\
\hline$\gamma_{\mathrm{M} 1}$ & $=$ & partial factor (EN 1993-1-1 2005); \\
\hline$\eta$ & $=$ & $0.00326\left(\lambda_{\mathrm{AS}}+\alpha_{\mathrm{a}} \alpha_{\mathrm{b}}-13.5\right) \geq 0(\mathrm{AS} 41001998)$ \\
\hline$\lambda$ & $=$ & non-dimensional member slenderness; \\
\hline$\lambda_{\text {AISC }}$ & $=$ & non-dimensional member slenderness for AISC 360 2005; \\
\hline$\lambda_{\mathrm{AS}}$ & $=$ & non-dimensional member slenderness for AS 4100 1998; \\
\hline$\lambda_{\mathrm{EC}}$ & $=$ & non-dimensional member slenderness for EN 1993-1-1 2005; \\
\hline$\omega$ & $=$ & lateral displacement at mid-height of column; \\
\hline$\omega_{\mathrm{g}}$ & $=$ & global imperfection amplitude; \\
\hline$\omega_{\mathrm{i}}$ & $=$ & initial global imperfection amplitude and \\
\hline$\xi$ & $=$ & $\frac{\left(\frac{\lambda_{\mathrm{AS}}+\alpha_{\mathrm{a}} \alpha_{\mathrm{b}}}{90}\right)^{2}+1+\eta}{2\left(\frac{\lambda_{\mathrm{AS}}+\alpha_{\mathrm{a}} \alpha_{\mathrm{b}}}{90}\right)^{2}}(\mathrm{AS} 41001998)$ \\
\hline
\end{tabular}




\section{References}

ABAQUS (2006). ABAQUS, Version 6.6, Hibbitt, Karlsson \& Sorensen, Inc. Pawtucket, USA.

Allen, H. G., and Bulson, P. S. (1980). Background to Buckling, McGraw-Hill, London.

AISC 360 (2005). Specification for structural steel buildings, AISC, Chicago, Illinois.

AS 1163 (1991). Structural steel hollow sections, Standards Australia, Homebush, New South Wales.

AS 4100 (1998). Steel structures, Standards Australia, Homebush, New South Wales.

ASTM A501 (2005). Standard specification for hot-formed welded and seamless carbon steel structural tubing, ASTM International, West Conshohocken, PA.

Ayrton, W. E., and Perry, J. (1886). “On struts.” The Engineer, 62, 464-465.

Bartlette, R. M., Dexter, R. J., Graeser, M., Jelinek, J. J., Schmidt, B. J. and Galambos, T. V. (2003). "Updating Standard Shape Material Properties Database for Design and Reliability." Engineering Journal, AISC, 40 (1), 2-14.

Batterman, R. H., and Johnston, B. G. (1967). "Behavior and maximum strength of metal columns." Journal of the Structural Division, ASCE, 93(2), 205-230. 
Beedle, L. S. (editor-in-chief) (1991). Stability of metal structures: $a$ world view, $2^{\text {nd }}$ Ed., Structural Stability Research Council, Lehigh University, Bethlehem, Pa.

Beer, H., and Schulz, G. (1970). "Bases théoriques des courbes européennes de flambement." Construction Métallique, 3, 37-57.

Bild, S., and Trahair, N. S. (1989). "In-plane strengths of steel columns and beamcolumns.” Journal of Constructional Steel Research, 13(1), 1-22.

Bjorhovde, R. (1972). Deterministic and probabilistic approaches to the strength of steel columns, $\mathrm{PhD}$ thesis, Lehigh University, Bethlehem, $\mathrm{Pa}$.

Bjorhovde, R. (1977). Strength and behaviour of cold-formed HSS columns, Structural Engineering Report No. 65, Department of Civil Engineering, the University of Alberta, Edmonton, Alta.

Bjorhovde, R. (1978). "The safety of steel columns." Journal of the Structural Division, ASCE, 104(3), 463-477.

Bjorhovde, R., and Tall, L (1971). Maximum column strength and the multiple column curve concept, Fritz Engineering Laboratory Report No. 338.29, Lehigh University, Bethlehem, $\mathrm{Pa}$.

Bortolotti, E., Jaspart, J. P., Pietrapertosa, C., Nicaud, G., Petitjean, P. D., and Grimault, J. P. (2003). "Testing and modelling of welded joints between elliptical 
hollow sections." Proceedings of the $10^{\text {th }}$ International Symposium on Tubular Structures, Madrid, Spain, 259-266.

Byfield, M. P. and Nethercot, D. A. (1997). "Material and geometric properties of structural steel for use in design.” The Structural Engineer, 75(21), 363-367

Chan, T. M. (2007). Structural behaviour of elliptical hollow sections, $\mathrm{PhD}$ thesis, Imperial College, London.

Chan, T. M., and Gardner, L. (2008a). "Compressive resistance of hot-rolled elliptical hollow sections.” Engineering Structures, 30(2), 522-532.

Chan, T. M., and Gardner, L. (2008b). "Bending strength of hot-rolled elliptical hollow sections.” Journal of Constructional Steel Research, 64(9), 971-986.

Choo, Y. S., Liang, J. X., and Lim, L. V. (2003). "Static strength of elliptical hollow section X-joint under brace compression.” Proceedings of the $10^{\text {th }}$ International Symposium on Tubular Structures, Madrid, Spain, 253-258.

Corus (2006a). Celsius ${ }^{\circledR} 355$ Ovals, Corus Tubes - Structural \& Conveyance Business.

Corus (2006b). Celsius ${ }^{\circledR} 355$ Ovals - Sizes and resistances Eurocode version, Corus Tubes - Structural \& Conveyance Business. 
Davison, T. A. and Birkemoe, P. C. (1983). "Column behaviour of cold-formed hollow structural steel shapes." Canadian Journal of Civil Engineering, 10(1), 125 141.

EN 1990 (2002). Eurocode 3 - Basis of structural design, CEN, Brussels, Belgium.

EN 1993-1-1 (2005). Eurocode 3: Design of steel structures - Part 1-1: General rules and rules for buildings, CEN, Brussels, Belgium.

EN 10210-2 (2006). Hot finished structural hollow sections of non-alloy and fine grain steels - Part 2: Tolerances, dimensions and sectional properties, CEN, Brussels, Belgium.

Galambos (editor) (1998). Guide to stability design criteria for metal structures, $5^{\text {th }}$ Ed., Wiley, New York.

Gardner, L., and Chan, T. M. (2007). "Cross-section classification of elliptical hollow sections." Steel and Composite Structures, 7(3), 185-200.

Gardner, L., Chan, T. M., and Wadee, M. A. (2008). "Shear response of elliptical hollow sections." Structures and Buildings, ICE. In press.

Gardner, L., and Nethercot, D. A. (2004). "Numerical modeling of stainless steel structural components - a consistent approach." Journal of Structural Engineering, ASCE, 130(10), 1586-1601. 
Jacquet, J. (1970). “Essais de flambement et exploitation statistique.” Construction Métallique, 3, 13-36.

Janns, J., Sedlacek, G., Maquoi, R., Ungermann, D., and Kuck, J. (1989). Background document 5.03 for chapter 5 of Eurocode 3 part 1 - Evaluation of test results on columns, beams and beam-columns with cross-sectional classes 1-3 in order to obtain strength functions and suitable model factors. Commission of the European Communities.

Maquoi, R., and Rondal, J. (1978). "Mise en équation des nouvelles courbes européennes de flambement.” Construction Métallique, 1, 17-30

Pietrapertosa, C., and Jaspart, J. P. (2003). "Study of the behaviour of welded joints composed of elliptical hollow sections." Proceedings of the $10^{\text {th }}$ International Symposium on Tubular Structures, Madrid, Spain, 601-608

Robertson, A. (1925). “The strength of struts”, Institution of Civil Engineers, Paper 28.

Rotter, J. M. (1982). "Multiple column curves by modifying factors." Journal of the Structural Division, ASCE, 108(7), 1665-1669.

Roufegarinejad, A., and Bradford, M. A. (2007). "Local buckling of thin-walled elliptical tubes containing an elastic infill." Proceedings of the $3^{\text {rd }}$ International 
Conference on Steel and Composite Structures, Manchester, United Kingdom, 943948.

Ruiz-Teran, A. M., and Gardner, L. (2008). "Elastic buckling of elliptical tubes.” Thin-Walled Structures, 46(11), 1304-1318.

Sfintesco, D. (1970). "Fondement expérimental des courbes européennes de flambement." Construction Métallique, 3, 5-12.

Stamenkovic, A., and Gardner, M. J. (1983). "Effect of residual stresses on the column behaviour of hot-finished steel structural hollow sections." Proceedings of the Institution of Civil Engineers, Part 2, 75, 599-616.

Tide, R. H. R. (1985). "Reasonable column design equations." Proceedings of the Annual Technical Session of Structural Stability Research Council, Cleveland, OH., $16^{\text {th }}-17^{\text {th }}$ April, 47-55.

Tide, R. H. R. (2001). “A technical note: Derivation of the LRFD column design equations.” Engineering Journal, AISC, 38(3), 137-139.

Trahair, N. S., and Bradford, M. A. (1998). The behaviour and design of steel structures to AS 4100, $3^{\text {rd }}$ Ed., E \& FN Spon, London.

Viñuela-Rueda, L., Martinez-Salcedo, J. (2006). "Steel structure and prestressed façade of the new terminal building.” Hormigón Y Acero, 239(1), 71-84. 
Willibald, S., Packer, J. A. and Martinez-Saucedo, G. (2006). "Behaviour of gusset plate connections to ends of round and elliptical hollow structural section members." Canadian Journal of Civil Engineering, 33(4), 373-383.

Yang, H., Lam, D. and Gardner, L. (2008). "Testing and analysis of concrete-filled elliptical hollow sections". Engineering Structures. In press.

Young, B., and Chen, J. (2008). "Design of Cold-Formed Steel Built-Up Closed Sections with Intermediate Stiffeners.” Journal of Structural Engineering, ASCE, 134(5), 727-737.

Zhao, X. L., Lu, H., and Galteri, S. (2007). "Tests of elliptical hollow sections filled with SCC (self-compacting concrete)." Proceedings of the $5^{\text {th }}$ International Conference on Advances in Steel Structures, Singapore, 950-955.

Zhu, Y., and Wilkinson, T. (2006). "Finite element analysis of structural steel elliptical hollow sections in pure compression." Proceedings of the $11^{\text {th }}$ International Symposium on Tubular Structures, Québec City, Canada, 179-186. 


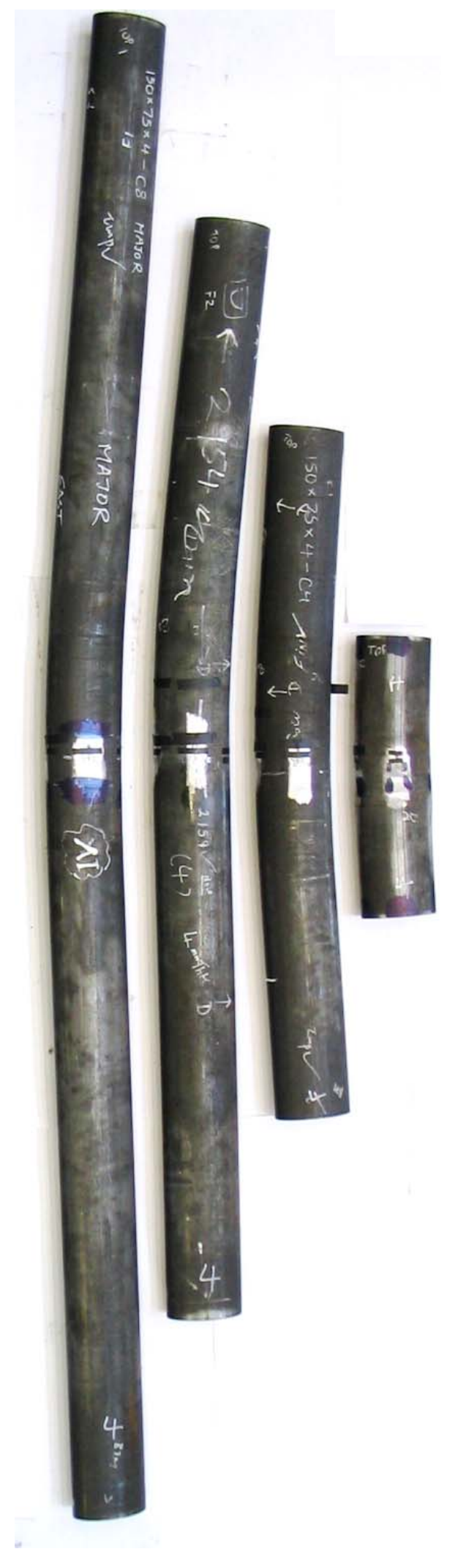

Fig. 1. Range of tested column lengths 


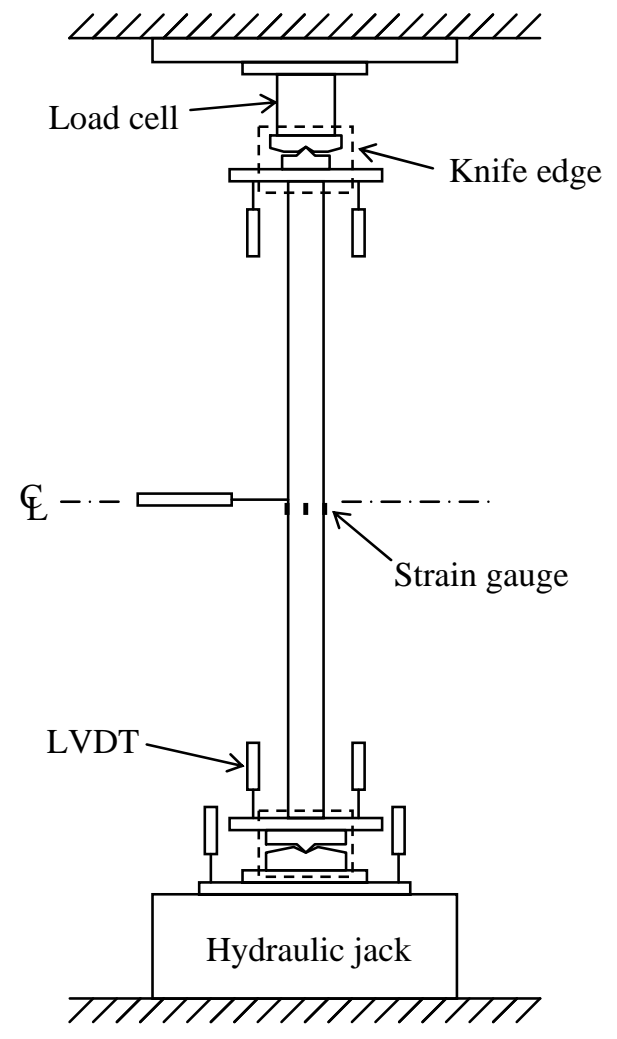

(a) Schematic setup

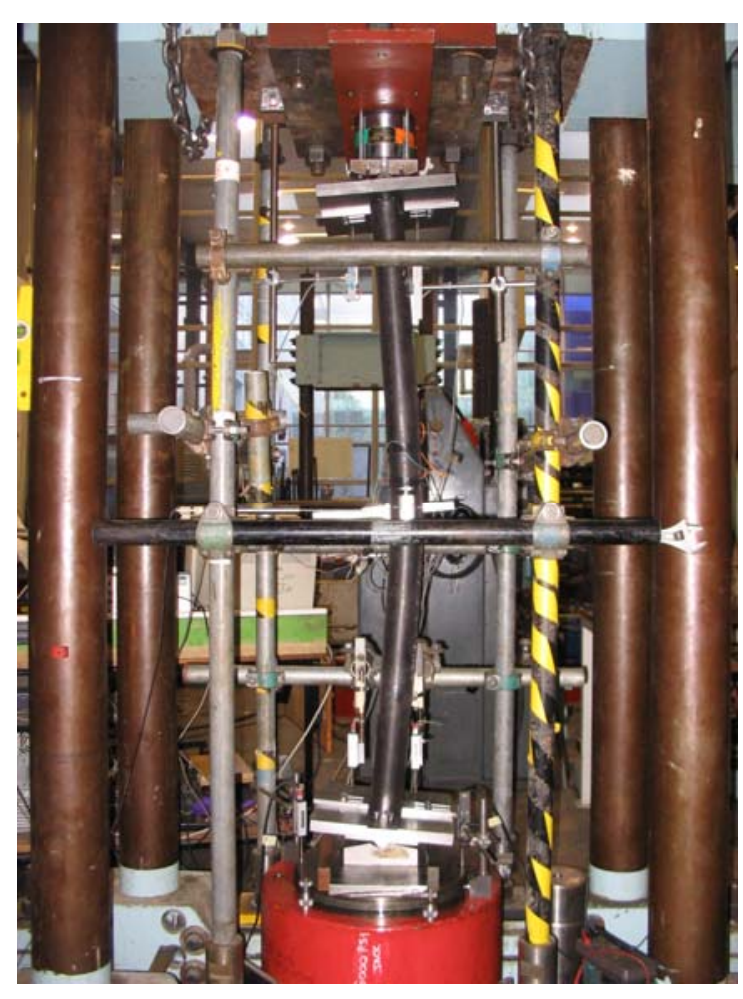

(b) Experimental setup

Fig. 2. Column test arrangement 


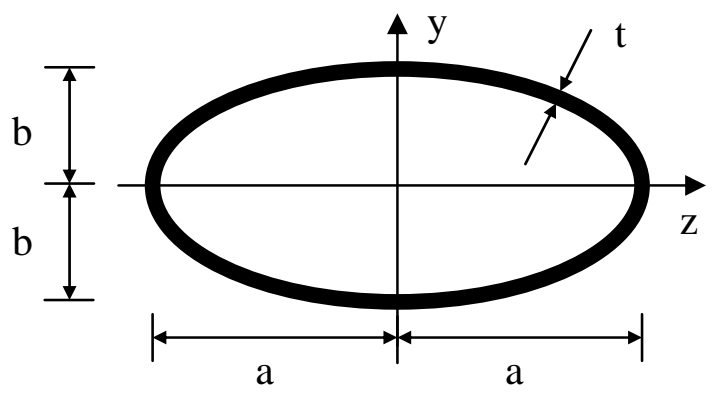

Fig. 3. Geometry of an elliptical hollow section 


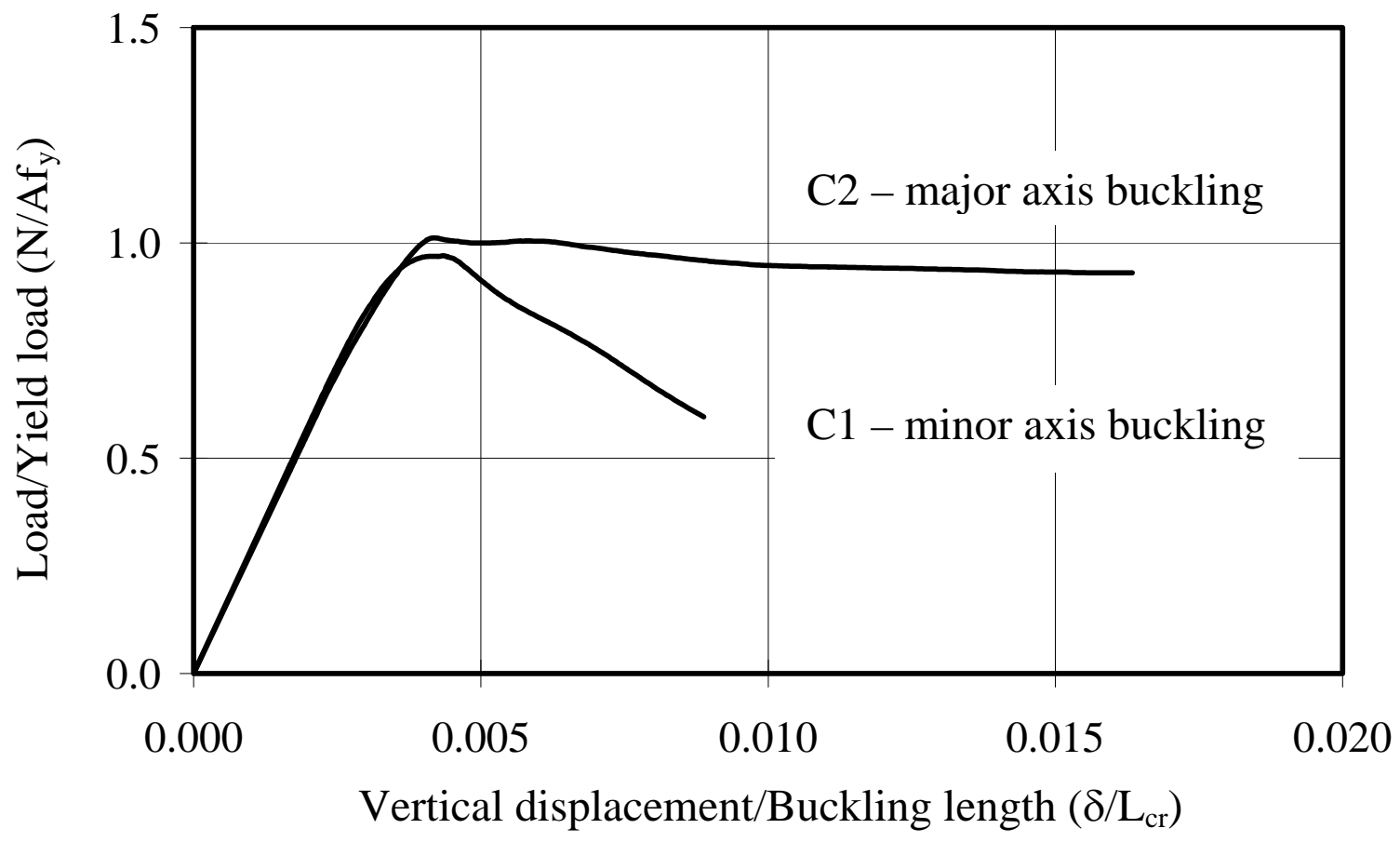

Fig. 4. $150 \times 75 \times 6.3$ column normalized load-vertical displacement curves 


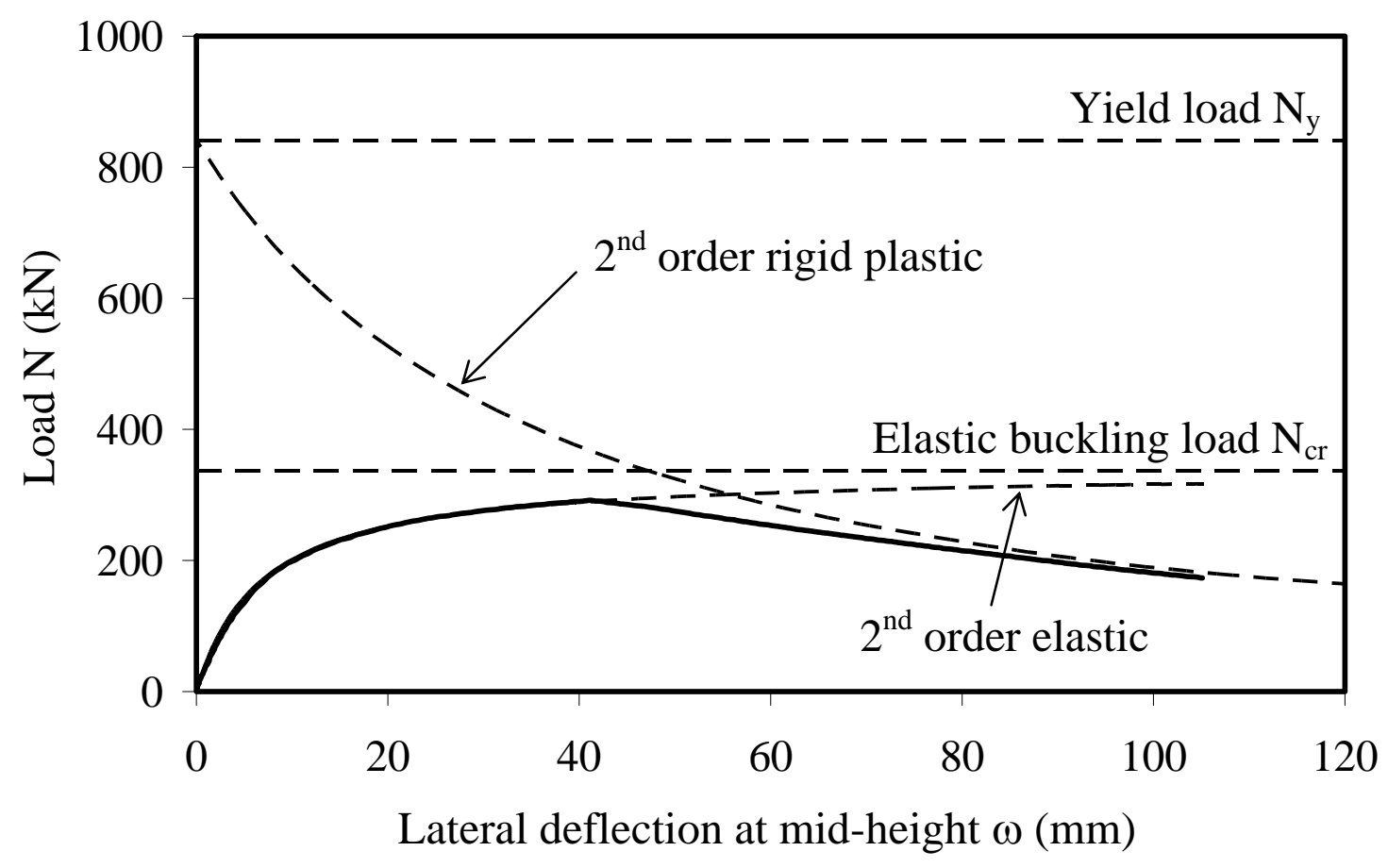

Fig. 5. $150 \times 75 \times 6.3-$ C7 column load-lateral deflection curve 


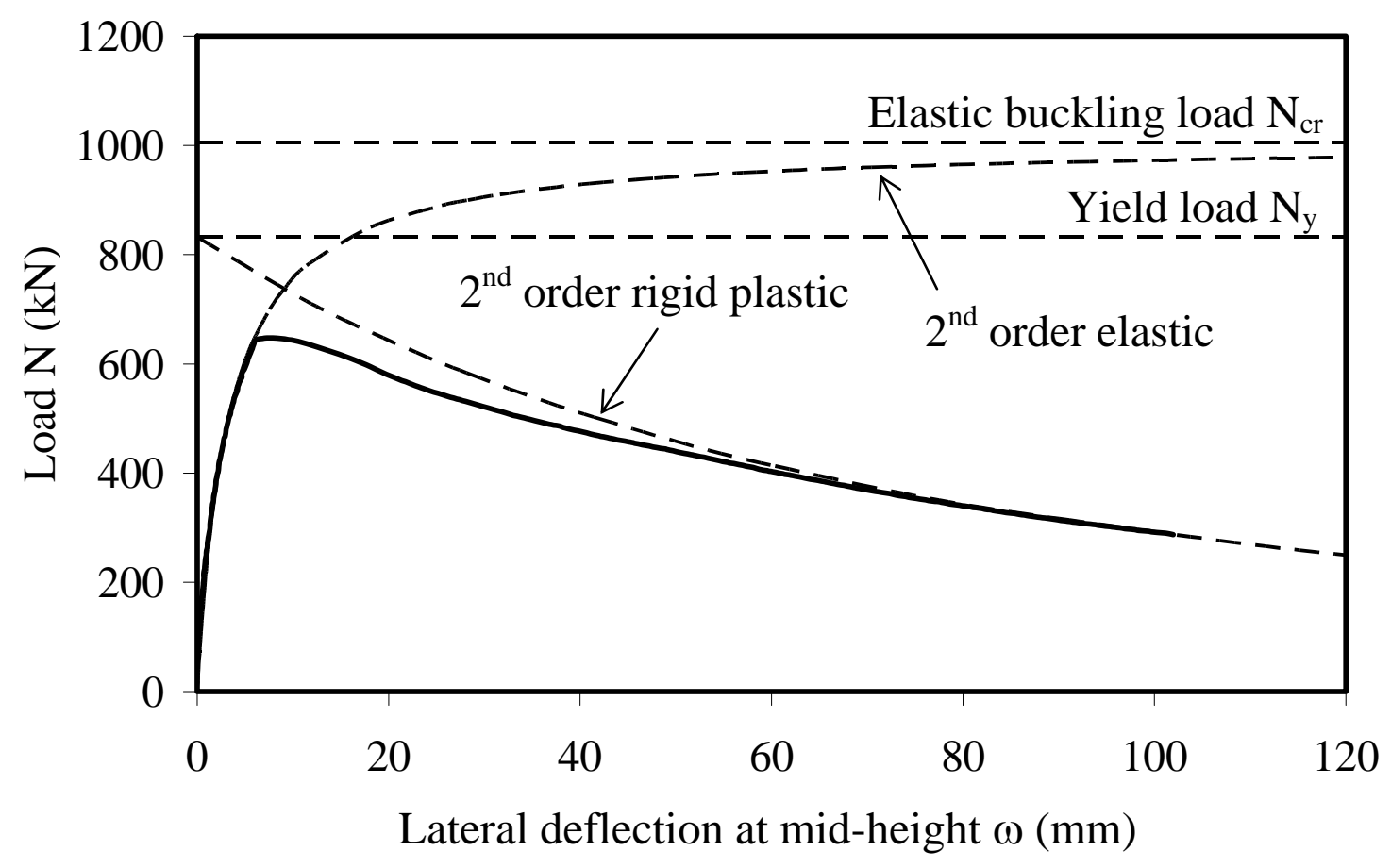

Fig. 6. $150 \times 75 \times 6.3-$ C8 column load-lateral deflection curve 


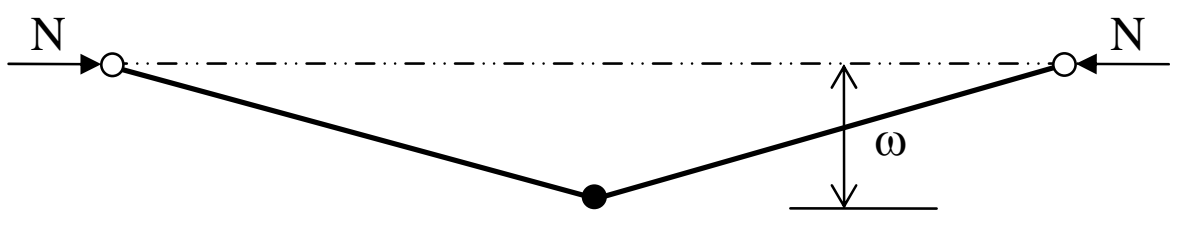

Fig. 7. Rigid plastic model 


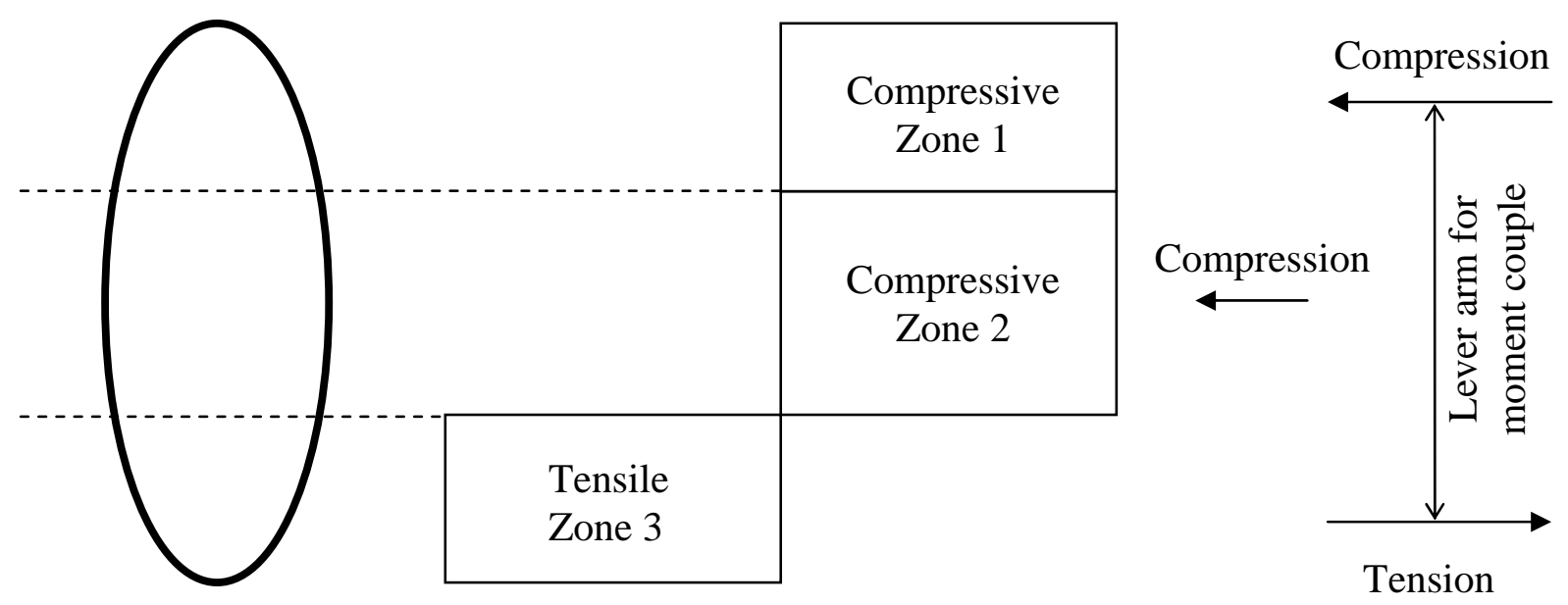

Fig. 8. Plastic stress distribution 

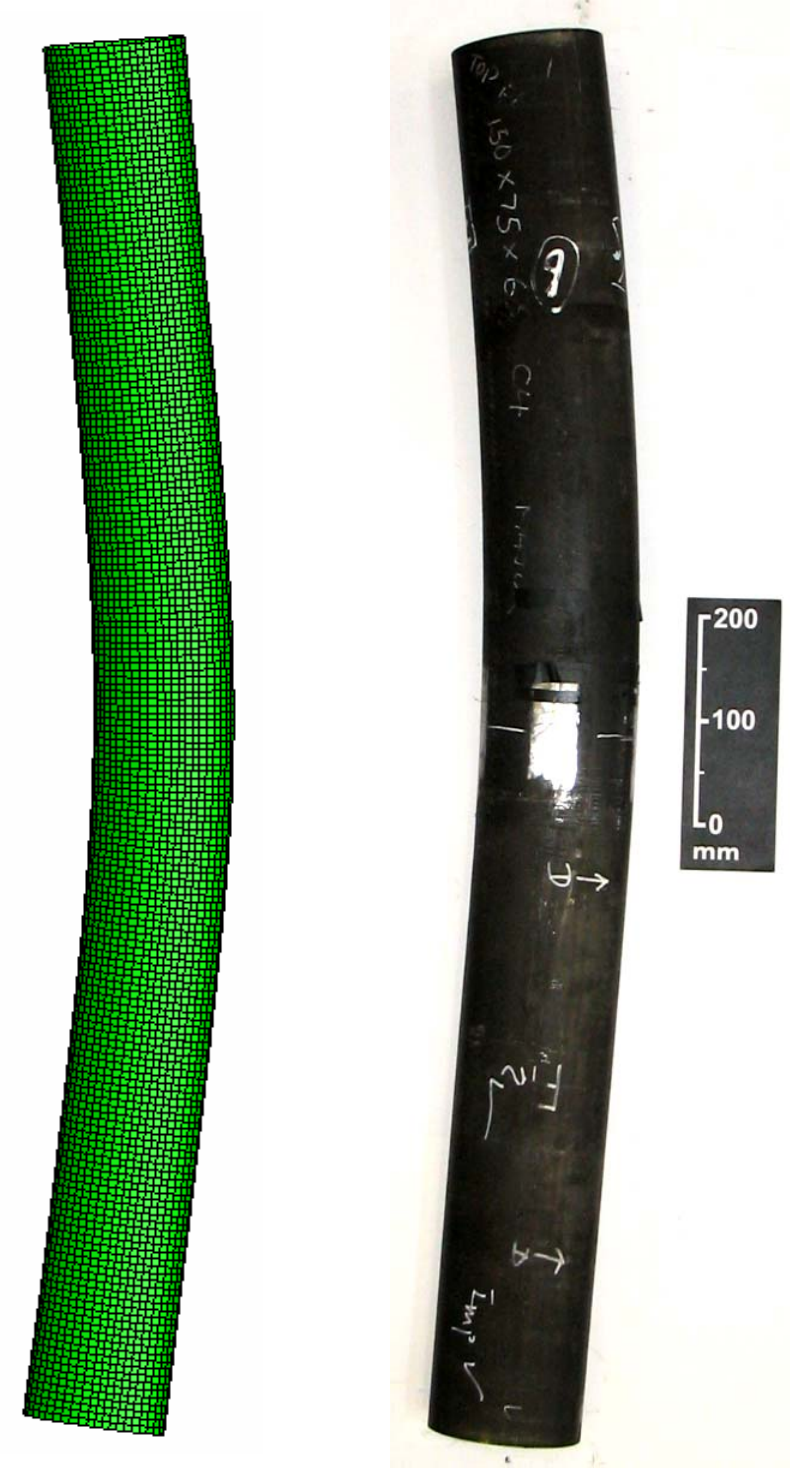

Fig. 9. Typical column failure mode $(150 \times 75 \times 6.3-$ C4 column $)$ 


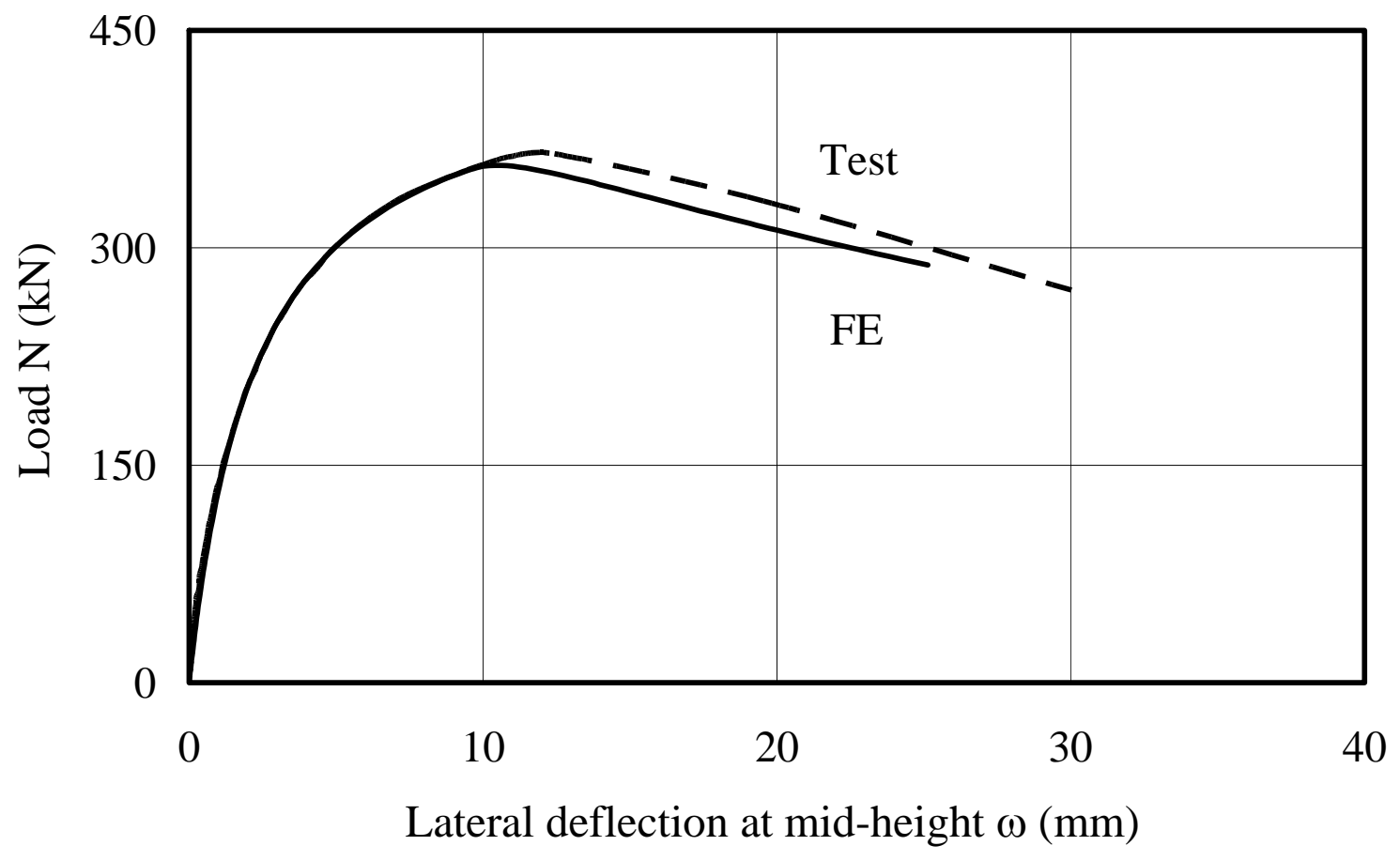

Fig. 10. $150 \times 75 \times 4-$ C5 column load-lateral deflection curves

$($ FE imperfection $=\mathrm{L} / 1000)$ 


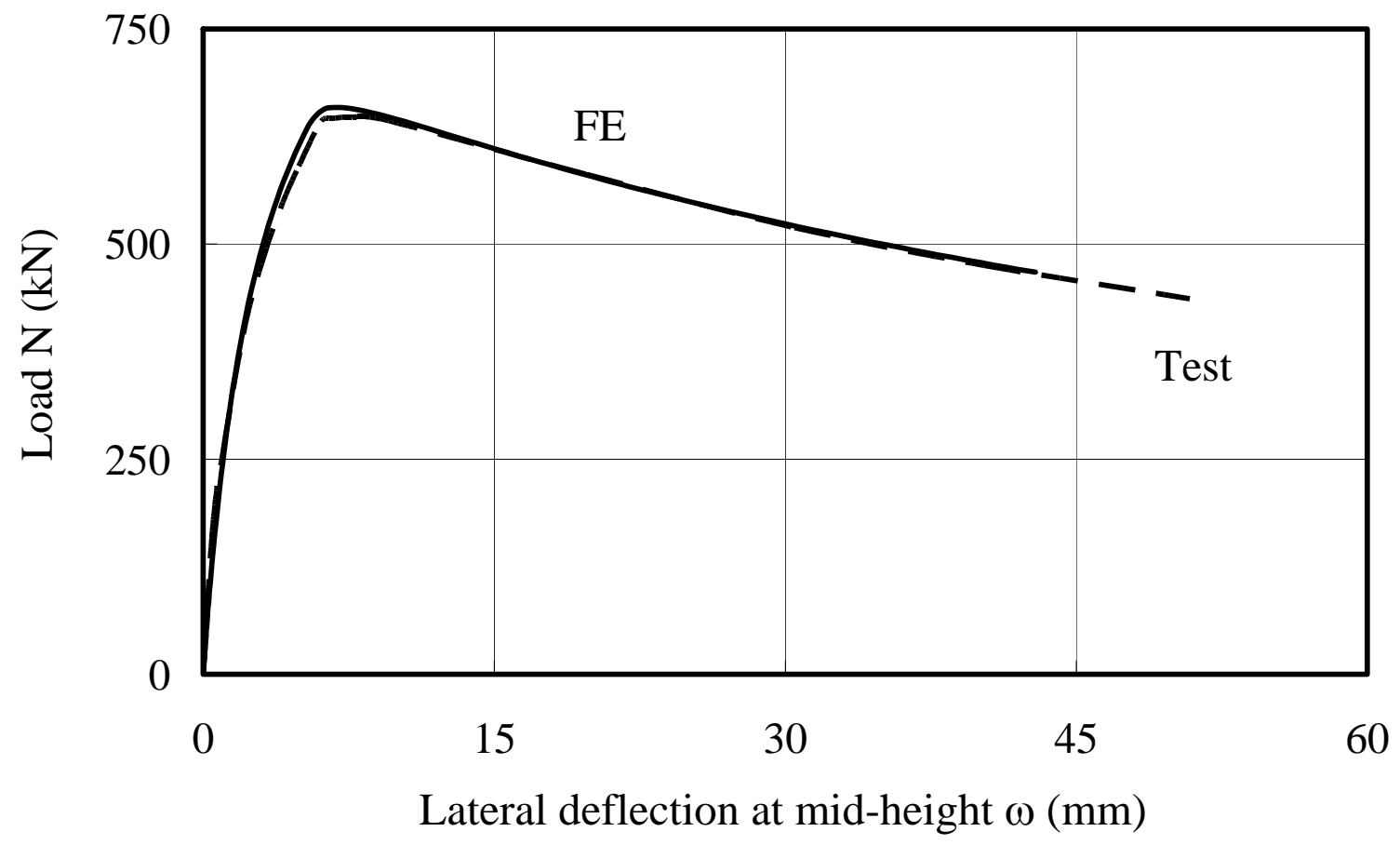

Fig. $11.150 \times 75 \times 6.3-$ C8 column load-lateral deflection curves

$($ FE imperfection $=\mathrm{L} / 1000)$ 


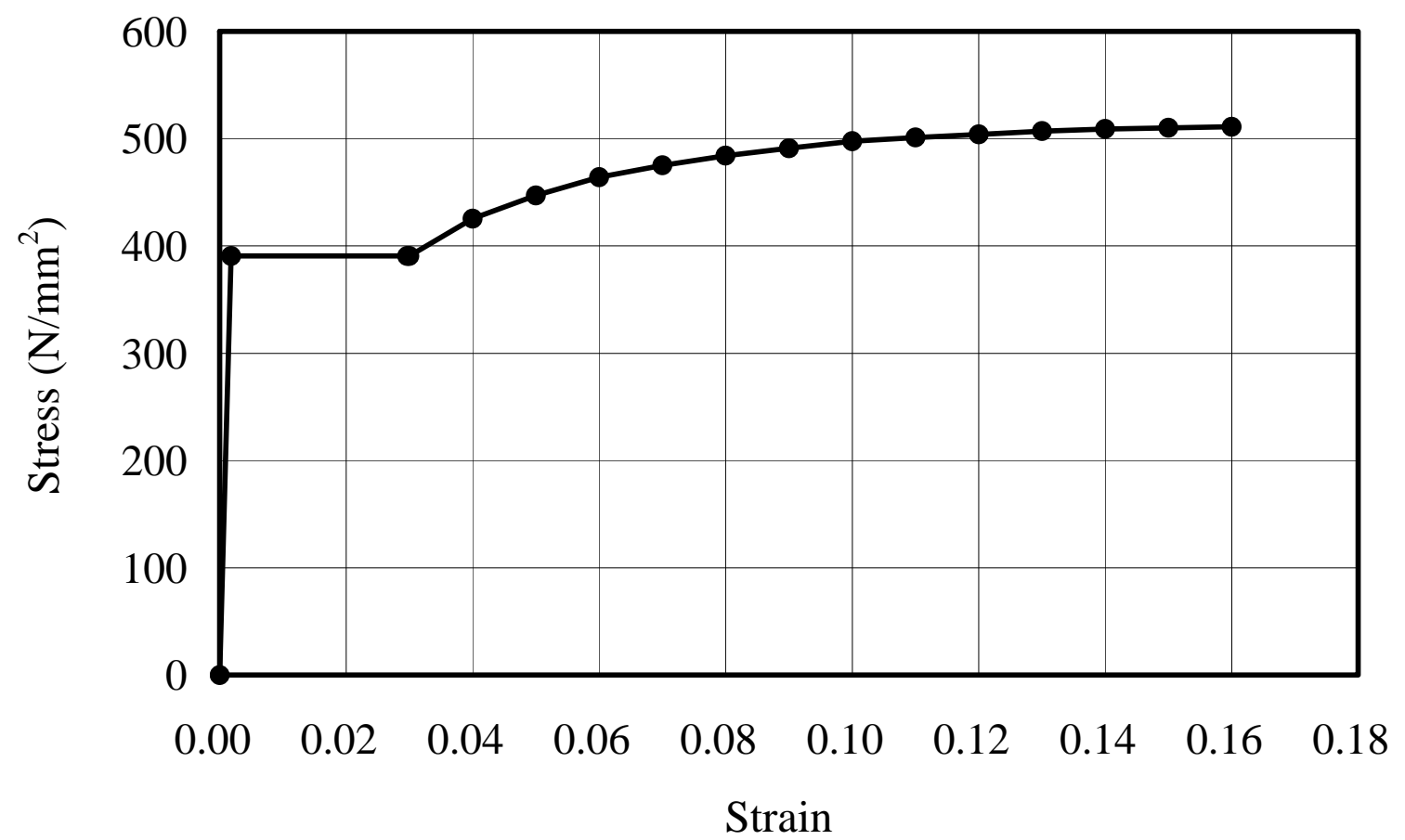

Fig. 12. Piecewise linear stress-strain model 


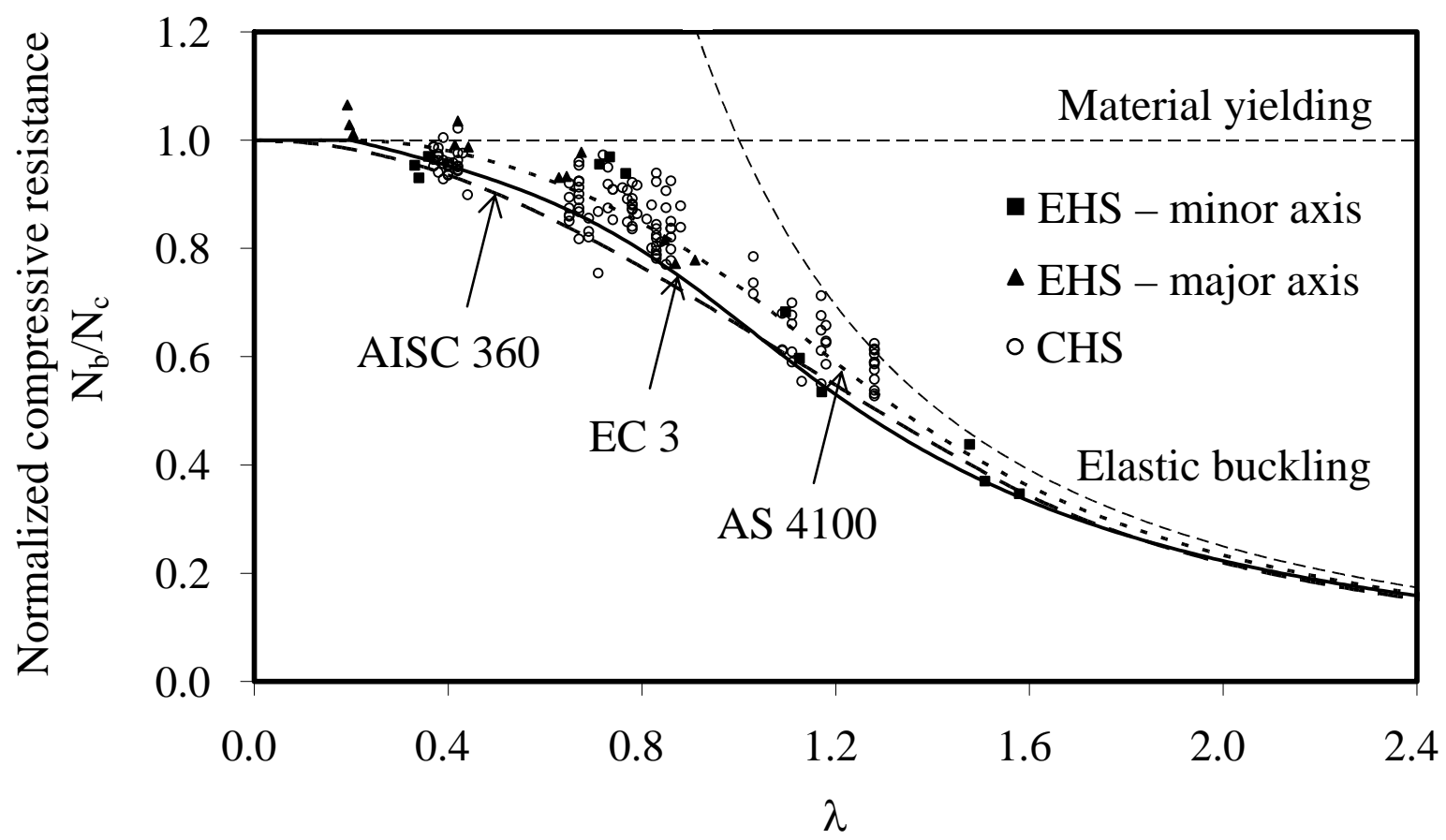

Non-dimensional slenderness

Fig. 13. Normalized test results and column buckling curves (nominal) 


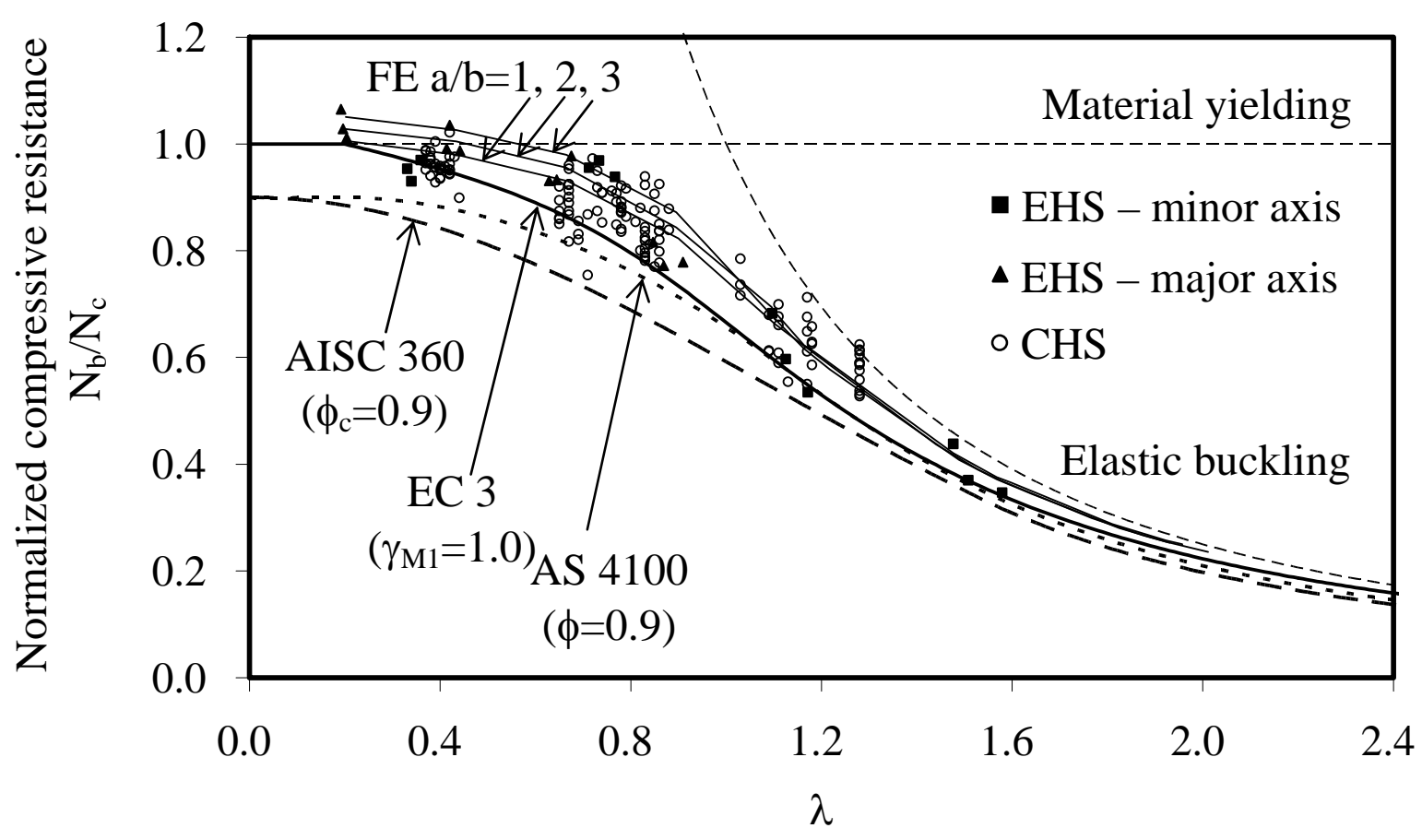

Non-dimensional slenderness

Fig. 14. Normalized test results and column buckling curves (design) 
Table 1. Mean measured dimensions and key results from the tensile coupons tests

\begin{tabular}{cccccc}
\hline Tensile coupons & $\begin{array}{c}\text { Width } \\
\mathrm{b}_{\mathrm{tc}} \\
(\mathrm{mm})\end{array}$ & $\begin{array}{c}\text { Thickness } \\
\mathrm{t} \\
(\mathrm{mm})\end{array}$ & $\begin{array}{c}\text { Young’s } \\
\text { modulus } \\
\mathrm{E} \\
\left(\mathrm{N} / \mathrm{mm}^{2}\right)\end{array}$ & $\begin{array}{c}\text { Yield stress } \\
\mathrm{f}_{\mathrm{y}} \\
\left(\mathrm{N} / \mathrm{mm}^{2}\right)\end{array}$ & $\begin{array}{c}\text { Ultimate } \\
\text { tensile stress } \\
\mathrm{f}_{\mathrm{u}} \\
\left(\mathrm{N} / \mathrm{mm}^{2}\right)\end{array}$ \\
\hline $150 \times 75 \times 4.0-\mathrm{TC} 1$ & 19.99 & 4.15 & 217400 & 380 & 512 \\
$150 \times 75 \times 4.0-\mathrm{TC} 2$ & 20.03 & 4.16 & 217700 & 373 & 514 \\
$150 \times 75 \times 5.0-\mathrm{TC} 1$ & 20.06 & 5.10 & 216900 & 374 & 506 \\
$150 \times 75 \times 5.0-\mathrm{TC} 2$ & 20.15 & 5.08 & 217200 & 364 & 503 \\
$150 \times 75 \times 6.3-\mathrm{TC} 1$ & 19.90 & 6.43 & 217700 & 381 & 509 \\
$150 \times 75 \times 6.3-\mathrm{TC} 2$ & 19.93 & 6.36 & 215200 & 400 & 515 \\
\hline
\end{tabular}


Table 2. Mean measured dimensions and key results from the column tests

\begin{tabular}{|c|c|c|c|c|c|c|c|}
\hline Columns & $\begin{array}{c}\text { Axis of } \\
\text { buckling }\end{array}$ & $\begin{array}{c}\text { Larger outer diameter } \\
2 \mathrm{a} \\
(\mathrm{mm})\end{array}$ & $\begin{array}{c}\text { Smaller outer diameter } \\
2 \mathrm{~b} \\
(\mathrm{~mm})\end{array}$ & $\begin{array}{l}\text { Thickness } \\
\text { t (mm) }\end{array}$ & $\begin{array}{l}\text { Buckling } \\
\text { Length } \\
\mathrm{L}_{\mathrm{cr}}(\mathrm{mm})\end{array}$ & $\begin{array}{c}\text { Measured maximum } \\
\text { global imperfection in } \\
\text { the direction of buckling } \\
\omega_{\mathrm{g}}(\mathrm{mm})\end{array}$ & $\begin{array}{l}\text { Ultimate load } \\
\quad \mathrm{N}_{\mathrm{u}}(\mathrm{kN})\end{array}$ \\
\hline $150 \times 75 \times 4.0-C 1$ & Minor & 150.56 & 75.48 & 4.14 & 700 & 0.29 & 495 \\
\hline $150 \times 75 \times 5.0-C 1$ & Minor & 150.08 & 76.00 & 5.13 & 700 & 0.10 & 614 \\
\hline $150 \times 75 \times 6.3-C 1$ & Minor & 150.37 & 75.25 & 6.27 & 700 & 1.23 & 820 \\
\hline $150 \times 75 \times 4.0-C 2$ & Major & 150.54 & 75.40 & 4.24 & 700 & 0.13 & 573 \\
\hline $150 \times 75 \times 5.0-C 2$ & Major & 150.21 & 75.64 & 5.11 & 700 & 0.15 & 677 \\
\hline $150 \times 75 \times 6.3-C 2$ & Major & 150.28 & 75.53 & 6.35 & 700 & 0.49 & 866 \\
\hline $150 \times 75 \times 4.0-C 3$ & Minor & 150.44 & 75.53 & 4.20 & 1500 & 0.15 & 507 \\
\hline $150 \times 75 \times 5.0-C 3$ & Minor & 150.31 & 75.48 & 5.19 & 1500 & 1.80 & 647 \\
\hline $150 \times 75 \times 6.3-C 3$ & Minor & 148.36 & 75.62 & 6.30 & 1500 & 0.20 & 789 \\
\hline $150 \times 75 \times 4.0-C 4$ & Major & 150.05 & 75.51 & 4.26 & 1500 & 0.43 & 538 \\
\hline $150 \times 75 \times 5.0-C 4$ & Major & 150.10 & 76.08 & 5.10 & 1500 & 0.38 & 680 \\
\hline $150 \times 75 \times 6.3-C 4$ & Major & 148.47 & 75.90 & 6.33 & 1500 & 0.25 & 836 \\
\hline $150 \times 75 \times 4.0-C 5$ & Minor & 150.26 & 75.40 & 4.22 & 2300 & 1.09 & 365 \\
\hline $150 \times 75 \times 5.0-C 5$ & Minor & 150.11 & 75.40 & 5.12 & 2300 & 3.38 & 393 \\
\hline $150 \times 75 \times 6.3-C 5$ & Minor & 148.82 & 75.92 & 6.31 & 2300 & 0.89 & 452 \\
\hline
\end{tabular}




\begin{tabular}{|c|c|c|c|c|c|c|c|}
\hline $150 \times 75 \times 4.0-\mathrm{C} 6$ & Major & 150.34 & 75.46 & 4.17 & 2300 & 0.46 & 489 \\
\hline $150 \times 75 \times 5.0-\mathrm{C} 6$ & Major & 150.05 & 75.54 & 5.09 & 2300 & 1.02 & 611 \\
\hline $150 \times 75 \times 6.3-\mathrm{C} 6$ & Major & 148.77 & 75.78 & 6.21 & 2300 & 0.25 & 814 \\
\hline $150 \times 75 \times 4.0-C 7$ & Minor & 150.50 & 75.45 & 4.22 & 3100 & 1.93 & 234 \\
\hline $150 \times 75 \times 5.0-C 7$ & Minor & 149.93 & 75.79 & 5.09 & 3100 & 1.55 & 242 \\
\hline $150 \times 75 \times 6.3-\mathrm{C} 7$ & Minor & 148.77 & 75.85 & 6.28 & 3100 & 0.74 & 292 \\
\hline $150 \times 75 \times 4.0-C 8$ & Major & 150.46 & 75.43 & 4.18 & 3100 & 0.25 & 429 \\
\hline $150 \times 75 \times 5.0-C 8$ & Major & 150.03 & 75.67 & 5.13 & 3100 & 1.32 & 509 \\
\hline $150 \times 75 \times 6.3-C 8$ & Major & 148.60 & 75.91 & 6.21 & 3100 & 0.42 & 648 \\
\hline
\end{tabular}


Table 3 Comparison of the column test results with FE results for varying imperfection amplitude $\omega_{\mathrm{g}}$

FE $\mathrm{N}_{\mathrm{u}} /$ Test $\mathrm{N}_{\mathrm{u}}$

\begin{tabular}{|c|c|c|c|c|c|}
\hline \multirow{2}{*}{ Columns } & \\
\hline & $\omega_{\mathrm{g}}=\mathrm{L} / 250$ & $\omega_{\mathrm{g}}=\mathrm{L} / 500$ & $\omega_{\mathrm{g}}=\mathrm{L} / 1000$ & $\omega_{\mathrm{g}}=\mathrm{L} / 2000$ & Measured $\omega_{\mathrm{g}}$ \\
\hline $150 \times 75 \times 4.0-\mathrm{C} 1$ & 1.00 & 1.05 & 1.08 & 1.09 & 1.10 \\
\hline $150 \times 75 \times 5.0-C 1$ & 0.96 & 1.02 & 1.04 & 1.07 & 1.07 \\
\hline $150 \times 75 \times 6.3-C 1$ & 0.92 & 0.97 & 1.00 & 1.02 & 0.98 \\
\hline $150 \times 75 \times 4.0-\mathrm{C} 2$ & 0.94 & 0.96 & 0.97 & 0.97 & 0.98 \\
\hline $150 \times 75 \times 5.0-\mathrm{C} 2$ & 0.93 & 0.95 & 0.96 & 0.96 & 0.97 \\
\hline $150 \times 75 \times 6.3-\mathrm{C} 2$ & 0.94 & 0.96 & 0.97 & 0.98 & 0.98 \\
\hline $150 \times 75 \times 4.0-\mathrm{C} 3$ & 0.78 & 0.90 & 0.98 & 1.03 & 1.08 \\
\hline $150 \times 75 \times 5.0-C 3$ & 0.73 & 0.84 & 0.92 & 0.97 & 0.90 \\
\hline $150 \times 75 \times 6.3-\mathrm{C} 3$ & 0.74 & 0.85 & 0.94 & 0.99 & 1.04 \\
\hline $150 \times 75 \times 4.0-C 4$ & 0.92 & 0.98 & 1.01 & 1.03 & 1.03 \\
\hline $150 \times 75 \times 5.0-C 4$ & 0.84 & 0.90 & 0.93 & 0.95 & 0.95 \\
\hline $150 \times 75 \times 6.3-C 4$ & 0.88 & 0.94 & 0.97 & 0.99 & 1.00 \\
\hline $150 \times 75 \times 4.0-C 5$ & 0.74 & 0.87 & 0.98 & 1.06 & 1.06 \\
\hline $150 \times 75 \times 5.0-C 5$ & 0.81 & 0.95 & 1.07 & 1.15 & 1.00 \\
\hline $150 \times 75 \times 6.3-C 5$ & 0.87 & 1.01 & 1.13 & 1.21 & 1.24 \\
\hline $150 \times 75 \times 4.0-C 6$ & 0.86 & 0.96 & 1.04 & 1.08 & 1.11 \\
\hline $150 \times 75 \times 5.0-C 6$ & 0.81 & 0.91 & 0.98 & 1.02 & 1.03 \\
\hline $150 \times 75 \times 6.3-\mathrm{C} 6$ & 0.76 & 0.86 & 0.93 & 0.97 & 1.00 \\
\hline $150 \times 75 \times 4.0-C 7$ & 0.76 & 0.87 & 0.94 & 0.98 & 0.97 \\
\hline $150 \times 75 \times 5.0-C 7$ & 0.86 & 0.98 & 1.07 & 1.12 & 1.12 \\
\hline $150 \times 75 \times 6.3-C 7$ & 0.87 & 0.98 & 1.05 & 1.10 & 1.12 \\
\hline $150 \times 75 \times 4.0-C 8$ & 0.80 & 0.94 & 1.05 & 1.14 & 1.25 \\
\hline $150 \times 75 \times 5.0-C 8$ & 0.80 & 0.94 & 1.06 & 1.14 & 1.16 \\
\hline $150 \times 75 \times 6.3-C 8$ & 0.77 & 0.90 & 1.02 & 1.11 & 1.21 \\
\hline MEAN & 0.85 & 0.94 & 1.00 & 1.05 & 1.06 \\
\hline COV & 0.09 & 0.06 & 0.06 & 0.07 & 0.09 \\
\hline
\end{tabular}


Table 4 Summary of normalized results from the column tests

\begin{tabular}{|c|c|c|c|}
\hline Columns & $\begin{array}{l}\text { Cross-section } \\
\text { classification } \\
\text { (compression) }\end{array}$ & $\mathrm{N}_{\mathrm{u}} / \mathrm{N}_{\mathrm{y}}$ or $\mathrm{N}_{\mathrm{u}} / \mathrm{A}_{\text {eff }} \mathrm{f}_{\mathrm{y}}$ & $\lambda_{\mathrm{EC}}$ \\
\hline $150 \times 75 \times 4.0-\mathrm{C} 1 *$ & Slender & 0.95 & 0.33 \\
\hline $150 \times 75 \times 5.0-\mathrm{C} 1$ & Fully effective & 0.93 & 0.34 \\
\hline $150 \times 75 \times 6.3-\mathrm{C} 1$ & Fully effective & 0.97 & 0.36 \\
\hline $150 \times 75 \times 4.0-\mathrm{C} 2 *$ & Slender & 1.07 & 0.19 \\
\hline $150 \times 75 \times 5.0-C 2$ & Fully effective & 1.03 & 0.20 \\
\hline $150 \times 75 \times 6.3-C 2$ & Fully effective & 1.01 & 0.20 \\
\hline $150 \times 75 \times 4.0-\mathrm{C} 3 *$ & Slender & 0.96 & 0.71 \\
\hline $150 \times 75 \times 5.0-C 3$ & Fully effective & 0.97 & 0.73 \\
\hline $150 \times 75 \times 6.3-\mathrm{C} 3$ & Fully effective & 0.94 & 0.77 \\
\hline $150 \times 75 \times 4.0-\mathrm{C} 4 *$ & Slender & 0.99 & 0.41 \\
\hline $150 \times 75 \times 5.0-C 4$ & Fully effective & 1.04 & 0.42 \\
\hline $150 \times 75 \times 6.3-C 4$ & Fully effective & 0.99 & 0.44 \\
\hline $150 \times 75 \times 4.0-\mathrm{C} 5 *$ & Slender & 0.68 & 1.10 \\
\hline $150 \times 75 \times 5.0-C 5$ & Fully effective & 0.60 & 1.13 \\
\hline $150 \times 75 \times 6.3-C 5$ & Fully effective & 0.53 & 1.17 \\
\hline $150 \times 75 \times 4.0-C^{*}$ & Slender & 0.93 & 0.63 \\
\hline $150 \times 75 \times 5.0-\mathrm{C} 6$ & Fully effective & 0.93 & 0.64 \\
\hline $150 \times 75 \times 6.3-\mathrm{C} 6$ & Fully effective & 0.98 & 0.68 \\
\hline $150 \times 75 \times 4.0-\mathrm{C} 7 *$ & Slender & 0.44 & 1.48 \\
\hline $150 \times 75 \times 5.0-C 7$ & Fully effective & 0.37 & 1.51 \\
\hline $150 \times 75 \times 6.3-C 7$ & Fully effective & 0.35 & 1.58 \\
\hline $150 \times 75 \times 4.0-\mathrm{C} 8 *$ & Slender & 0.82 & 0.85 \\
\hline $150 \times 75 \times 5.0-C 8$ & Fully effective & 0.77 & 0.87 \\
\hline $150 \times 75 \times 6.3-C 8$ & Fully effective & 0.78 & 0.91 \\
\hline
\end{tabular}

* Results normalized by $\mathrm{A}_{\text {eff }} \mathrm{f}_{\mathrm{y}}$ 
Table 5. Summary of statistical analysis parameters for EN 1990 (2002)

\begin{tabular}{ccccccc}
\hline Data set & No. of tests & $\mathrm{k}_{\mathrm{d}, \mathrm{n}}$ & $\mathrm{b}$ & $\mathrm{V}_{\delta}$ & $\mathrm{V}_{\mathrm{r}}$ & $\gamma_{\mathrm{M} 1}$ \\
\hline Test results & 24 & 3.56 & 1.083 & 0.0567 & 0.0735 & 1.02 \\
Test + FE results & 48 & 3.31 & 1.076 & 0.0463 & 0.0656 & 0.99 \\
\hline
\end{tabular}


Table 6. Summary of statistical analysis parameters for AISC 360 (2005)

\begin{tabular}{cccccc}
\hline Data set & No. of tests & $\mathrm{V}_{\mathrm{Q}}$ & $\mathrm{V}_{\mathrm{R}}$ & $\phi_{\mathrm{c}}$ & $\beta$ \\
\hline Test results & 24 & 0.20 & 0.11 & 0.9 & 3.11 \\
Test + FE results & 48 & 0.20 & 0.10 & 0.9 & 3.17 \\
\hline
\end{tabular}

